\title{
ARQUITECTURA DOMÉSTICA TARDOANTIGUA EN CORDUBA. TOPOGRAFÍA, URBANÍSTICA Y FUNCIONALIDAD
}

\section{RESIDENTIAL ARCHITECTURE IN LATE ANTIQUE CORDUBA. TOPOGRAPHY, URBANISM AND FUNCTIONALITY}

\author{
MANUEL D. RUIZ-BUENO \\ Departamento de Historia del Arte, Arqueología y Música. \\ Facultad de Filosofía y Letras. Plaza del Cardenal Salazar no 3, 14071, Córdoba, España. \\ Correo-e: mdruizbueno@gmail.com ORCID: http://orcid.org/0000-0001-9265-6979
}

Resumen: Entre las diferentes transformaciones que acaecieron en la Antigüedad Tardía, destaca la desigual evolución de la arquitectura doméstica urbana. A lo largo de este extenso período tuvo lugar el ennoblecimiento de las residencias de las clases más privilegiadas; la desaparición de las domus de peristilo y su frecuente transformación en casas familiares; la entrada en escena de un novedoso modelo de residencia aristocrática, o la aparición de una nueva arquitectura doméstica popular. Aun cuando Córdoba debió de participar en dichas dinámicas, la desigual calidad y antigüedad de la documentación arqueológica no siempre ha permitido documentarlas de forma adecuada. Gracias a la revisión crítica de dicha información, hemos podido profundizar en diversas cuestiones topográficas, urbanísticas y funcionales que han sido contextualizadas a escala peninsular, con el fin de ofrecer la imagen más completa posible del período comprendido entre los siglos II y VII d.C.

Palabras clave: Arquitectura doméstica; domus; Antigüedad Tardía; Hispania; Colonia Patricia; Corduba.
Abstract: Among the numerous transformations that took place in Late Antiquity, one of the most noteworthy is the differences in how urban domestic architecture developed. Throughout this long period of time, several trends can be seen: the embellishment of the houses belonging to the most privileged classes; the disappearance of the Roman peristyle houses and their transformation into buildings shared by several families; the emergence of a new model of upper-class residence, and the appearance of a new, popular style of domestic architecture. Even though these trends must have occurred in Cordoba, the archaeological information is scarce and this makes it difficult to draw any clear conclusions. However, after analysing all the available information, we have been able to delve into some of the topographical, urbanistic and functional issues affecting domestic architecture in the Iberian Peninsula. The aim of this paper is to provide as complete a picture as possible in the period from the $2^{\text {nd }}$ to the $7^{\text {th }}$ centuries AD.

Keywords: Residential architecture; Domus; Late Antiquity; Hispania; Colonia Patricia; Corduba. 


\section{INTRODUCCIÓN}

"La particular problemática urbanistica de la ciudad de Córdoba, que ocupa el mismo solar desde su fundación, unida a las limitaciones de la investigación arqueológica que en ella se viene desarrollando-particularmente desde los mediados del siglo $X X$ - son causa, aún hoy, de un desconocimiento casi total del urbanismo y de la arquitectura domésticos de época romana, y por consiguiente de su evolución precisa en el tiempo" (Vaquerizo 2004: 81).

Hace más de diez años, D. Vaquerizo puso de relieve el limitado y desigual conocimiento sobre la arquitectura doméstica del caput provinciae bético. Por entonces, los estudios se limitaban en gran medida a un par de breves síntesis sobre la evolución de las viviendas cordubenses (Carrillo 1999; Vaquerizo 2004), y a determinados trabajos que abordaron la decoración musivaria (Moreno González 1996 y 1997); la infraestructura hidráulica doméstica (Ventura 1996: 67 ss. y 116-125) y algunas viviendas (Secilla y Márquez 1991; Ventura y Carmona 1992). Aunque en los últimos años el panorama se ha enriquecido gracias al hallazgo de nuevos inmuebles residenciales (con frecuencia aún inéditos), las investigaciones se han focalizado eminentemente en uno de los barrios extramuros (Cánovas 2010; Castro y Cánovas 2009-2010), y en diversos establecimientos residenciales aislados de carácter suburbano o periurbano (Penco 2005, Salinas 2005, Ortiz 2011, Vaquerizo 2014).

Por el contrario, y frente a otras ciudades hispanorromanas como Astigi (García-Dils 2015: 287-446), Augusta Emerita (Corrales 2016), Barcino (Cortes 2011), Bracara Augusta (Magalhães 2010), Conimbriga (Correia 2010) o Hispalis (González 2011: 236 ss.), en Córdoba no disponemos de un estudio monográfico que haya analizado la arquitectura residencial en época clásica. Dicho vacío es extensible al período tardoantiguo, cuando las viviendas evolucionaron de forma desigual.

El heterogéneo destino de la arquitectura doméstica romana hunde sus raíces en la variada tipología de estructuras urbanas propias de época altoimperial. Frente a la visión tradicional, no hubo un solo tipo de vivienda, sino múltiples soluciones adaptadas a los distintos poderes adquisitivos y al estatus social de cada familia (Fernández 2003: 411 ss.; 2011; González 2011: 235, Cortés 2014). Si excluimos la morada de los sintecho, tenemos un variado elenco de inmuebles que incluyen casae y tuguria simples (que no suelen contar con un área central de circulación ni de distribución); inmuebles con un espacio distribuidor cubierto o descubierto; tabernae, trastiendas y celdas con función residencial; bloques de pisos (insulae), etc. No obstante, la mayor parte de las ciudades recurrieron a un aprovechamiento horizontal del suelo, de modo que las clases más privilegiadas optaron por residir en viviendas unifamiliares ricamente ornamentadas. Conocidas con el nombre de domus, consistían en construcciones articuladas alrededor de uno o varios patios y que ocuparon buena parte de la superficie in urbe.

Esta última dinámica, extensible a numerosas ciudades hispanorromanas, es la que se ha documentado en Córdoba. En el estado actual de la investigación, y si tomamos como punto de partida la primera mitad del siglo II d.C., el espacio intramuros del caput provinciae bético (de unas 78 ha de extensión) parece haber estado ocupado en gran medida por viviendas unifamiliares pertenecientes generalmente a individuos con un considerable nivel socioeconómico. Si bien es cierto que debieron existir otras edificaciones más modestas (en las que habitaría el grueso de la población), la documentación arqueológica se limita en gran medida a tabernae (todavía mal conocidas) que probablemente combinaron la función económica con la habitacional.

Al igual que otras urbes, la Córdoba romana no se ciñó al espacio intramuros, sino que se expandió más allá de sus murallas. Desde momentos tardorrepublicanos y augusteos (Murillo et al. 2009: 693-694), pero sobre todo a partir de los comedios del siglo I d.C. (Vaquerizo y Murillo 2010: 479), fueron configurándose varios barrios suburbanos de carácter eminentemente doméstico. Por último, a una mayor distancia de la ciudad, tenemos algunos establecimientos de carácter suburbano o periurbano que en ocasiones tuvieron un marcado componente residencial (Vaquerizo 2014).

La imagen que acabamos de exponer no tardó mucho tiempo en modificarse, puesto que desde mediados del siglo II d.C. en adelante, la arquitectura doméstica de la capital bética se vio inmersa en varias transformaciones no siempre bien documentadas. Factores tan variados como la antigüedad y/o metodología de determinadas intervenciones arqueológicas; el reducido tamaño de los solares excavados; el desigual conocimiento acerca del registro material propio de época tardoantigua, y el hecho de que no contemos con una sola vivienda (intramuros o extramuros) cuya planta se conozca en su totalidad, han dificultado el estudio de la arquitectura residencial. Ante tales obstáculos, hemos optado por centrarnos en aspectos eminentemente topográficos, urbanísticos y funcionales. Tales cuestiones han sido contextualizadas a escala peninsular con 
el fin de reflejar el panorama existente entre los siglos II y VII d.C., y especialmente, a lo largo de la Antigüedad Tardía.

\section{MEDIADOS DEL SIGLO II- INICIOS DEL III d.C.}

El advenimiento de la dinastía antonina trajo consigo algunos cambios en la arquitectura urbana hispanorromana. El siglo II d.C. supuso el triunfo definitivo de la domus de peristilo (que desplazó definitivamente al modelo de casa de atrio); la construcción de nuevas viviendas y, sobre todo, la remodelación de las viviendas preexistentes, "ya fuera por dotar a los inmuebles de una nueva distribución o bien para engrandecer la estructura doméstica con nuevos ámbitos" (Romero 2016: 351). Entre los espacios que más atención recibieron tenemos los peristilos y triclinios, donde "se focaliza la inversión como demuestra el estudio de la musivaria" (Romero 2016: 352).

En el caso de Córdoba, el mayor auge de la producción musivaria (empleada eminentemente en la arquitectura doméstica), tuvo lugar entre mediados del siglo II y comienzos del III d.C. De los más de 205 suelos de tesellatum y sectile cordobeses conocidos hasta la fecha, alrededor del $43 \%$ han sido fechados en este reducido marco temporal (Ruiz Osuna y Ruiz 2018). Se trata de un fenómeno que dista de ser local, al haberse constatado en otras ciudades del valle del Guadalquivir caracterizadas por el florecimiento de la mencionada industria durante los siglos II y III d.C., como es el caso de Astigi (López Monteagudo 2010: 370-371), y a lo largo de la dinastía antoniniana e inicios de la severiana, tal y como resulta evidente en Italica (Mañas 2009: 197).

\subsection{El espacio intramuros}

En la superficie in urbe de Colonia Patricia disponemos de una considerable muestra de mosaicos (fechados por lo general mediante criterios estilísticos) adscritos, con mayor o menor seguridad, a ambientes domésticos. En su mayor parte, son pavimentos recuperados hace varias décadas, por lo que no podemos precisar si reflejan la construcción o reforma de una vivienda (Moreno González 1996). Por fortuna, intervenciones arqueológicas más recientes han permitido identificar fenómenos como la renovación del aparato decorativo de algunas domus preexistentes (Secilla y Márquez 1991:
341; Moreno González 1996: 81 y 84); la remodelación a gran escala (quizás ampliación) de un inmueble doméstico previo (Pérez Navarro 2003: 66-68) y la construcción de determinadas viviendas cuya planta no se conoce con precisión (Montejo 1998: 33, Ruiz Nieto 1999: 126 ss., Valderrama 2007, Ruiz Bueno 2014: 47). Especialmente significativo es tanto la edificación de inmuebles domésticos en puntos hasta entonces libres de construcciones (Montejo 1998: 30), como la construcción o ampliación de determinadas viviendas a costa de determinados ejes viarios (Ruiz Bueno 2014: 46-47, 2014-2015: 102). Si a este último dato añadimos la ausencia de viviendas claramente abandonadas en estos momentos, la imagen que se dibuja es la de una superficie in urbe con una elevada demanda de espacio habitable.

\subsection{El espacio extramuros}

Este dinamismo y vitalidad también es evidente en los barrios suburbanos (fig. 1). Gracias a antiguos hallazgos musivarios y a las excavaciones realizadas en los últimos años, conocemos varias dinámicas datadas en este marco temporal. Destaca el recurrente empleo de suelos de mosaico y de sectile; la reorganización interna de algunos inmuebles domésticos; la densificación interna de determinados barrios, y su expansión más allá de sus límites tradicionales (Moreno González 1996, Cánovas 2010: 424-426, Vargas 2010: 455-457, Ruiz Bueno 2016: 165-171). En el caso del barrio occidental, lo más significativo fue su crecimiento en dirección norte (fig. 2), ya que supuso la anulación de una antigua área cementerial monumental, que pasó a ser ocupada por estructuras de carácter doméstico y comercial (Murillo et al. 2002: 263-266). En cuanto al barrio extramuros oriental, el abandono del circo en el último cuarto del siglo II d.C. parece haber sido coetáneo a la instalación de viviendas no solo al norte del inmueble (Ruiz Nieto 2002: 157), sino también en la superficie ocupada por el antiguo edificio lúdico, al haberse identificado una vivienda levantada en las primeras décadas del siglo III d.C. en un punto correspondiente con la antigua arena (Murillo et al. 2010: 505, Ruiz Osuna y Ruiz 2018).

Nos encontramos por tanto ante un evidente florecimiento y auge de la arquitectura doméstica, motivado presumiblemente por la prosperidad económica de la ciudad en estas fechas. Dicha coyuntura es extensible a varias ciudades del curso medio y bajo del Guadalquivir, donde el registro arqueológico refleja la construcción, reforma o monumentalización de numerosos 


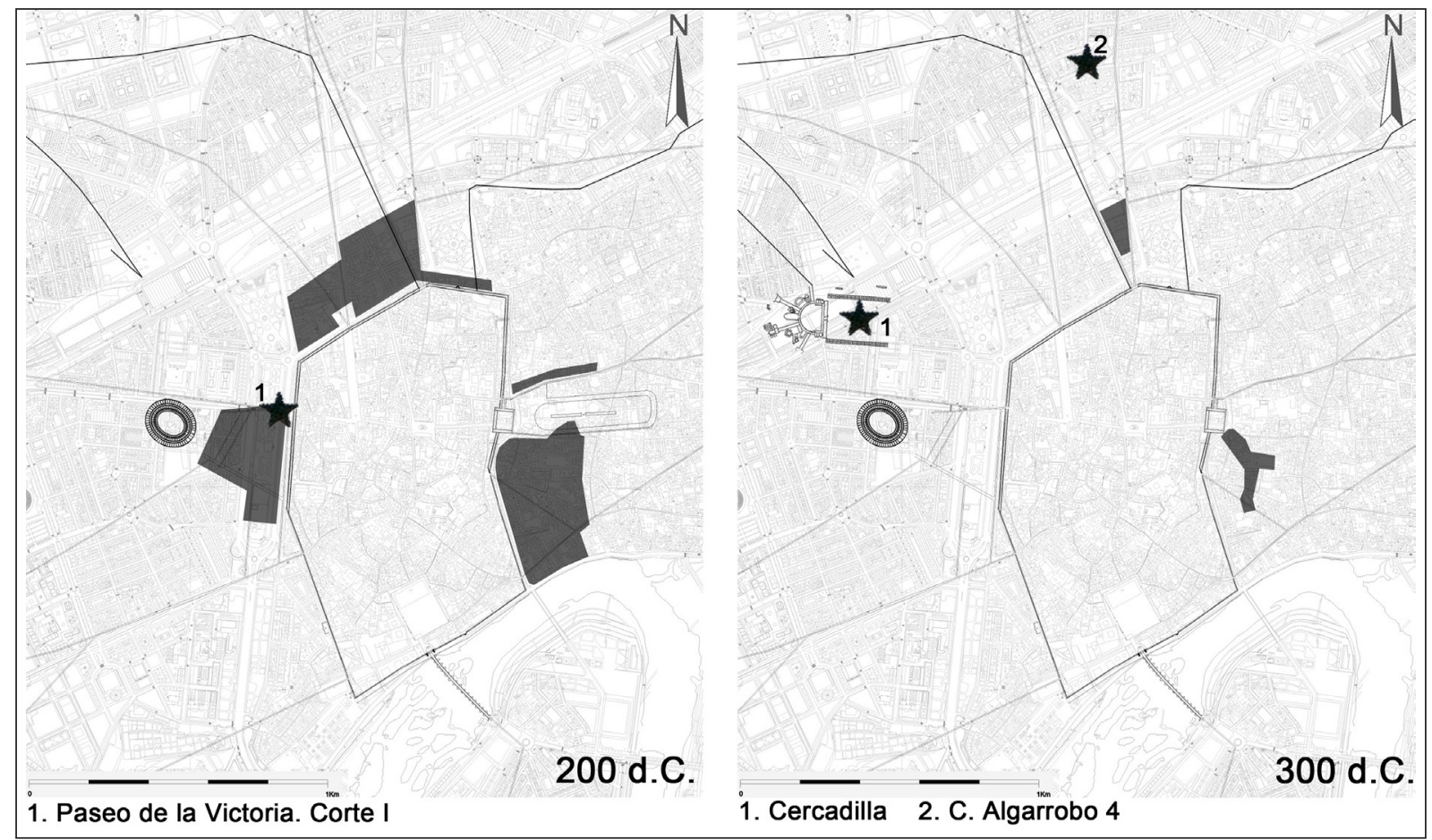

Figura 1. Extensión hipotética de los barrios extramuros que rodeaban a la Córdoba romana e indicación de las principales construcciones suburbanas mencionadas en el texto.

inmuebles situados eminentemente en la superficie intramuros. En este grupo incluimos a Astigi, donde se ha identificado con frecuencia una fase constructiva doméstica que abarca "la mitad o el final del siglo II" (Sáez et al. 2005: 101); Hispalis, con un fuerte impulso edilicio hacia la primera mitad del siglo II d.C. consolidado a partir del segundo cuarto de la centuria (González 2011: 248 ss.), e Italica, que conoció un florecimiento en época adrianea que se mantuvo en gran medida entre mediados del siglo II y comienzos del III d.C. En este último marco temporal arrancó un lento pero progresivo abandono del modelo urbano de la nova urbs italicense, que fue coetáneo tanto a la construcción de nuevas viviendas monumentales, como a la renovación del aparato decorativo de determinadas domus (Mañas 2009: 197, Román Rodríguez 2010: 294 ss.).

\section{SIGLOS III-IV d.C.}

La arquitectura doméstica cordobesa no permaneció ajena a los cambios socioeconómicos que afectaron al Imperio desde finales de época severiana y especialmente, con el advenimiento de la Tetrarquía y la posterior dinastía constantiniana.
Entre los fenómenos más destacados tenemos la reorientación del evergetismo, puesto que desde las primeras décadas del siglo III d.C. en adelante ha podido detectarse una disminución de las actividades evergéticas públicas (Melchor 2016: 237 y 238). Dicho descenso parece estar motivado por un cambio de mentalidad de las élites, quienes empezaron a redirigir parte de sus recursos hacia otras construcciones como las residencias urbanas y rurales (Melchor 1994: 195, 2009: 407-408). No olvidemos que las viviendas, sobre todo las aristocráticas, eran el escenario tradicional donde mostrar el rango, el prestigio y la posición de un individuo (Bowes 2010: 89). Este rol se acentuó a partir de la tercera centuria y a lo largo de la siguiente, cuando determinadas domus fueron sometidas a una importante monumentalización por causas no del todo conocidas. Frente a las interpretaciones tradicionales, que insistían en factores como la concentración de la riqueza, un cambio en la forma del patronazgo y el deseo de imitar la arquitectura áulica (Ellis 1998: 573, Baldini 2001: 47, 2005: 14-17), en la actualidad hay voces que han optado por poner el acento en las reformas administrativas de época tetrárquica y constantiniana. En este sentido, la notable expansión de la burocracia central y local iniciada con Diocleciano y 
Figura 2. Av. Paseo de la Victoria (Corte I). Estructuras domésticas y comerciales levantadas en la segunda mitad del siglo II d.C. en una antigua área funeraria. Modificado a partir de Murillo et al. 2002: fig. 19.

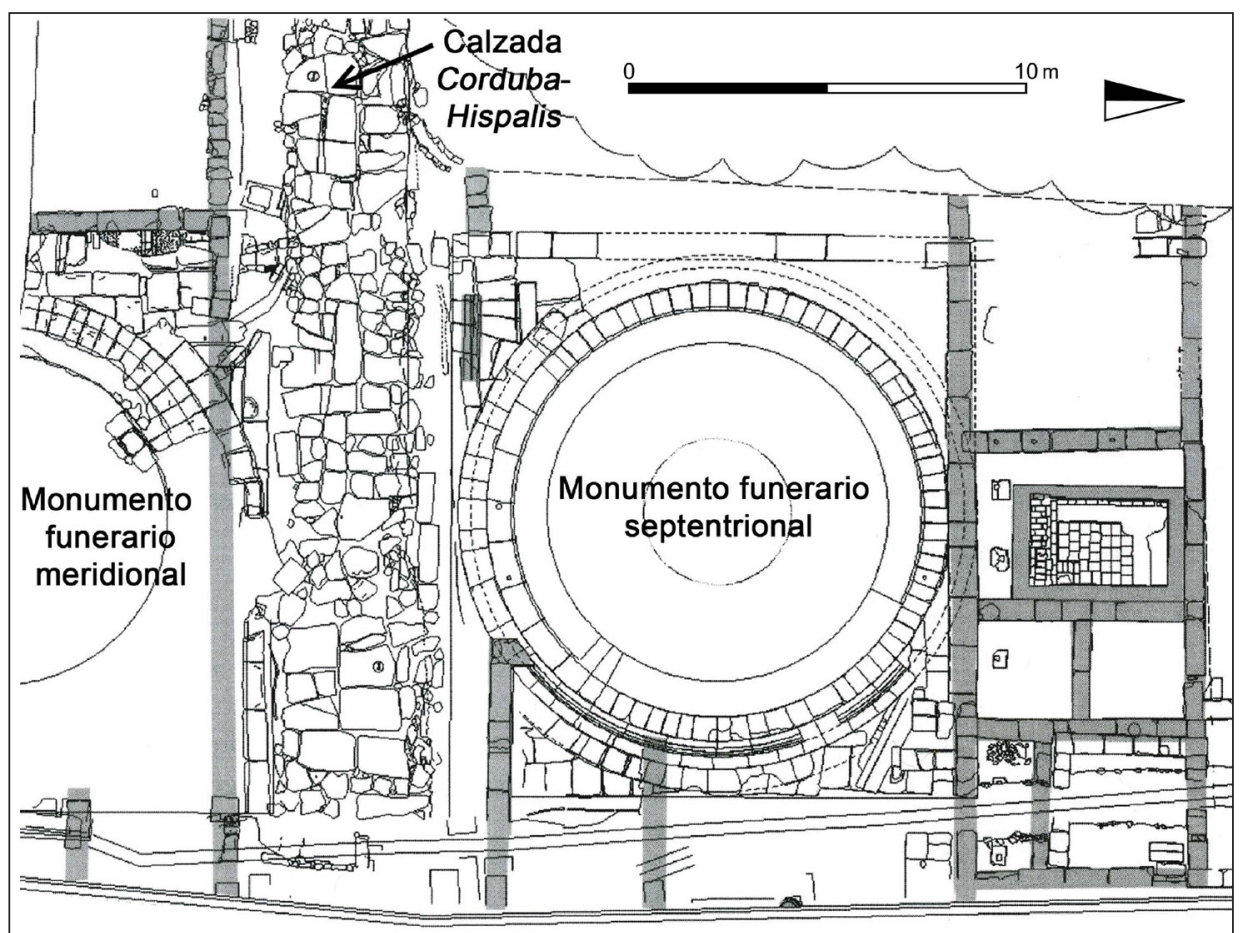

continuada por Constantino implicó "not simply more elites, but more heterogeneous, more competitive elites" (Bowes 2010: 89), que optaron por monumentalizar sus residencias, dando como resultado unos inmuebles que "should be understood not as products of hierarchization, but as hotspots of social competition" (Bowes 2010: 17).

Esta coyuntura influyó decisivamente en la arquitectura doméstica aristocrática, al haberse detectado, a lo largo y ancho del Imperio, la construcción, y sobre todo reforma, de determinadas viviendas que presentan una serie de rasgos muy característicos. Entre ellos tenemos su rica decoración musivaria y/o pictórica; $\mathrm{su}$ articulación alrededor de uno o varios espacios abiertos; la presencia de un variado elenco de espacios de representación polifucionales y de balnea privados; la invasión ocasional de determinados espacios públicos, y la notable superficie ocupada (Baldini 2001: 47 ss., 2005: 33 ss., Perich 2014a: 129-133). De hecho, para M. Alba (2004: 78) "el baremo más fiable para sopesar la riqueza de una casa-familia no son sus mosaicos ni la calidad de su pintura mural, sino el porte $y$ extensión de su(s) patio(s) y la extensión de metros útiles del inmueble".

Al margen de las suntuosas residencias aristocráticas, las ciudades siguieron albergando otras edificaciones domésticas como domus cuyos habitantes "non presentano una capacità económica sufficiente a sostenere le spese di una lussuosa risitemazione delle case già esistenti", por lo que recurrieron "a piccoli interventi di restauro, spesso poco evidente, e sopratutto opere di manutenzione, rivelando nel tempo una progressiva semplificazione delle strutture originarie" (Baldini 2005: 17). Tampoco podemos olvidar otras estructuras domésticas con o sin espacio distribuidor (cubierto o descubierto); tabernae, etc. (Baldini 2005: 17-19, Ellis 2006, Bowes 2010: 38-39).

Si nos centramos en Colonia Patricia, que desde mediados del siglo III d.C. recuperó el topónimo prerromano de Corduba (Ventura 1996: 204), el registro arqueológico ha puesto de relieve una desigual evolución de las construcciones domésticas, incluyendo su aparato decorativo. Así, el gran período de esplendor de la industria musivaria cordobesa fue seguido en el tiempo por una etapa (siglos III-IV d.C.) caracterizada por un progresivo descenso en la producción (Ruiz Osuna y Ruiz 2018), que también resulta evidente en otras ciudades como Italica (Mañas 2009: 180, 194 y 198) o Tarraco (Macías 2013: 127) y que contrasta con la situación general en la península ibérica, puesto que "the great age of mosaic production in the Iberian peninsula was the later third and especially the fourth century A.D" (Dunbabin 1999: 152). 


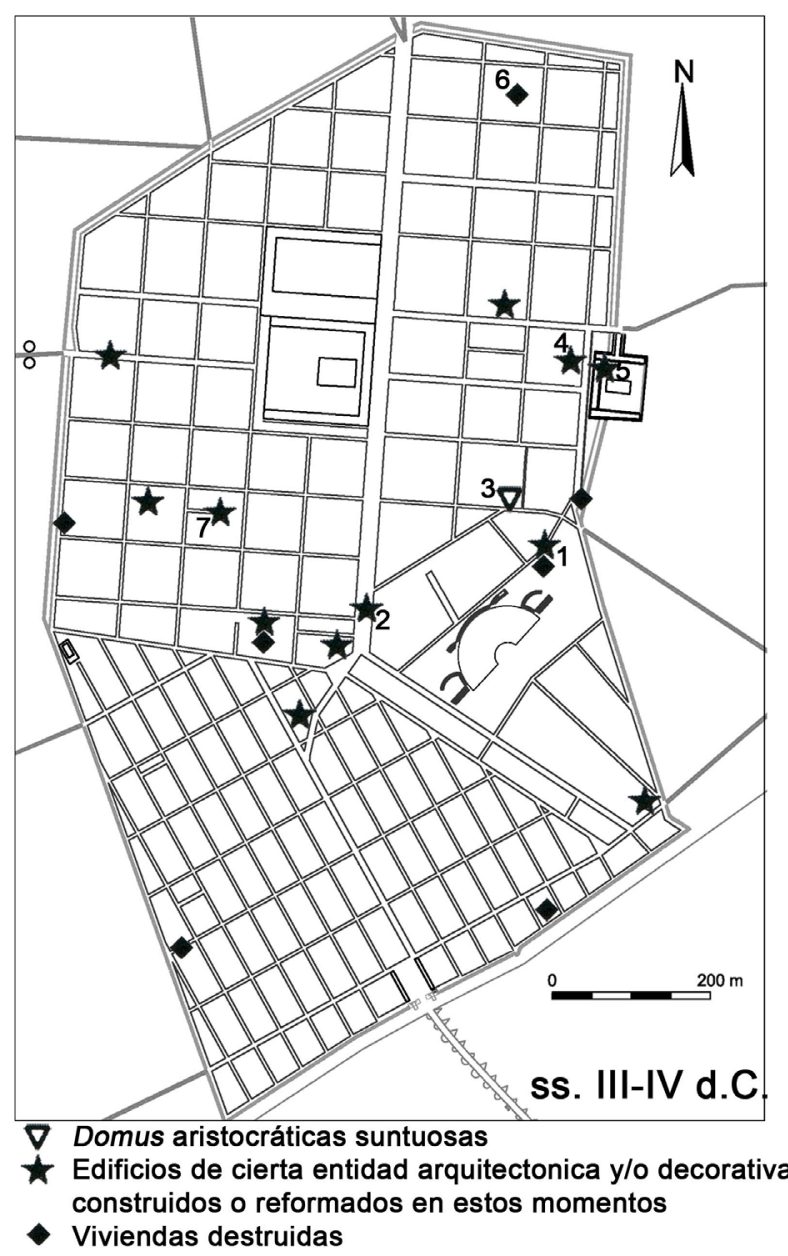

$\begin{array}{ll}\text { 1. C. Ambrosio de Morales } 20 & \text { 5. C. María Cristina } 7 \\ \text { 2. C. Ángel de Saavedra } 9 & \text { 6. C. Ramirez de las } \\ \text { 3. Pl. de la Compañía 5-9 } & \text { Casas-Deza 10-12 }\end{array}$

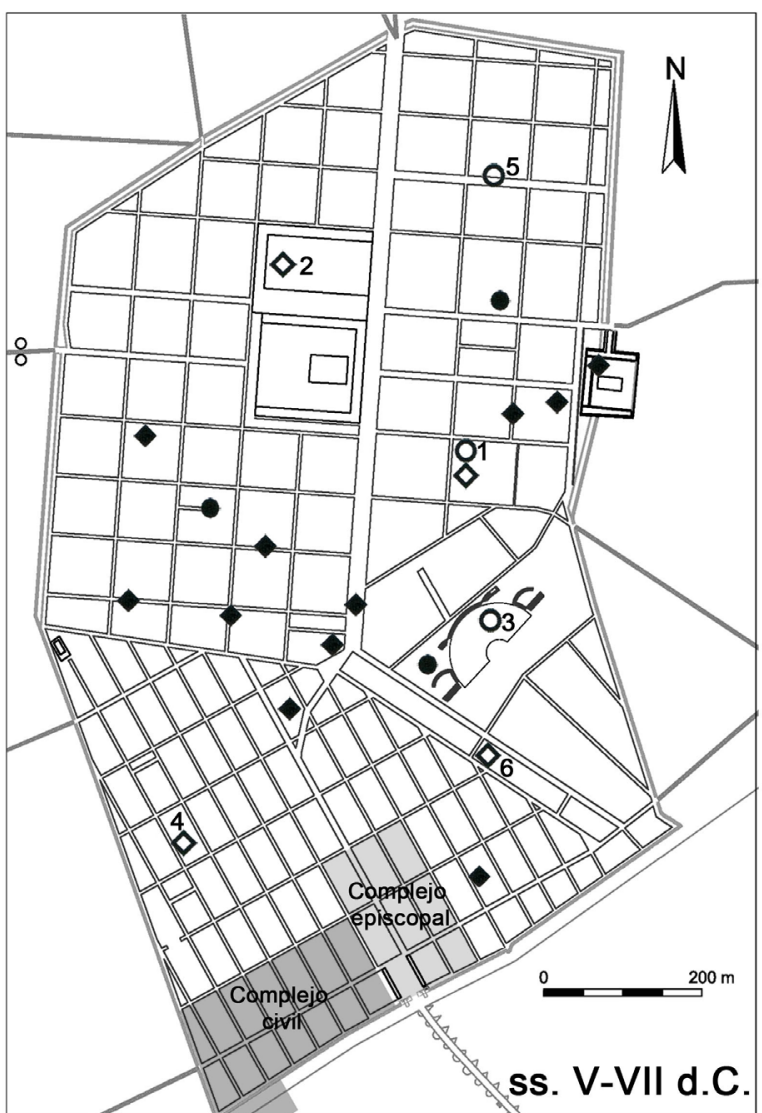

Inmuebles preexistentes habitados hasta los ss. VI-VII

O Arquitectura domestica de carácter popular

$\diamond$ Edificios de nueva planta vinculados a las elites

- Viviendas aparentemente abandonadas hacia el siglo V
1. C. Duque de Hornachuelos 8
5. C. Ramírez de las
2. C. Góngora 8
Casas-Deza 13
3. PI. de Jerónimo Páez 7

4. PI. de Maimonides 1

Figura 3. Arquitectura doméstica in urbe de Corduba con indicación de los principales solares mencionados en el texto. Nota: el callejero representado es el vigente hacia el año 100 d.C.

\subsection{El espacio intramuros}

En relación con la superficie intramuros (fig. 3) y frente a otras ciudades como Augusta Emerita (Alba 2005: 126-130), Barcino (Cortes 2011: 41-56), Complutum (Rascón y Sánchez 2015: 209-212) o Hispalis (González 2011: 308 ss.), en Córdoba apenas tenemos constancia de la existencia de lujosas domus aristocráticas construidas o reformadas en el siglo III y, sobre todo, en el IV d.C. La principal excepción es un mosaico con decoración geométrica y figurada (donde aparecen representadas las cuatro estaciones) que se ha venido fechando en la segunda mitad del siglo IV d.C. (Moreno
González 1996: 141), o con posterioridad a los años 30 del siglo V d.C. (Nicolini 1983: 86). Este pavimento (fig. 4), descubierto en 1871 en plaza de la Compañía 5-9, ornamentó una estancia perteneciente presumiblemente a una gran domus construida o remodelada en estas fechas.

Más difícil es determinar si esta muestra tan reducida de viviendas suntuosas está motivada por la parcialidad del registro arqueológico disponible (existen amplias zonas in urbe donde apenas se ha intervenido arqueológicamente), o bien, se debe a una reinversión de los recursos de las élites hacia determinadas unidades domésticas y/o productivas suburbanas y periurbanas. 


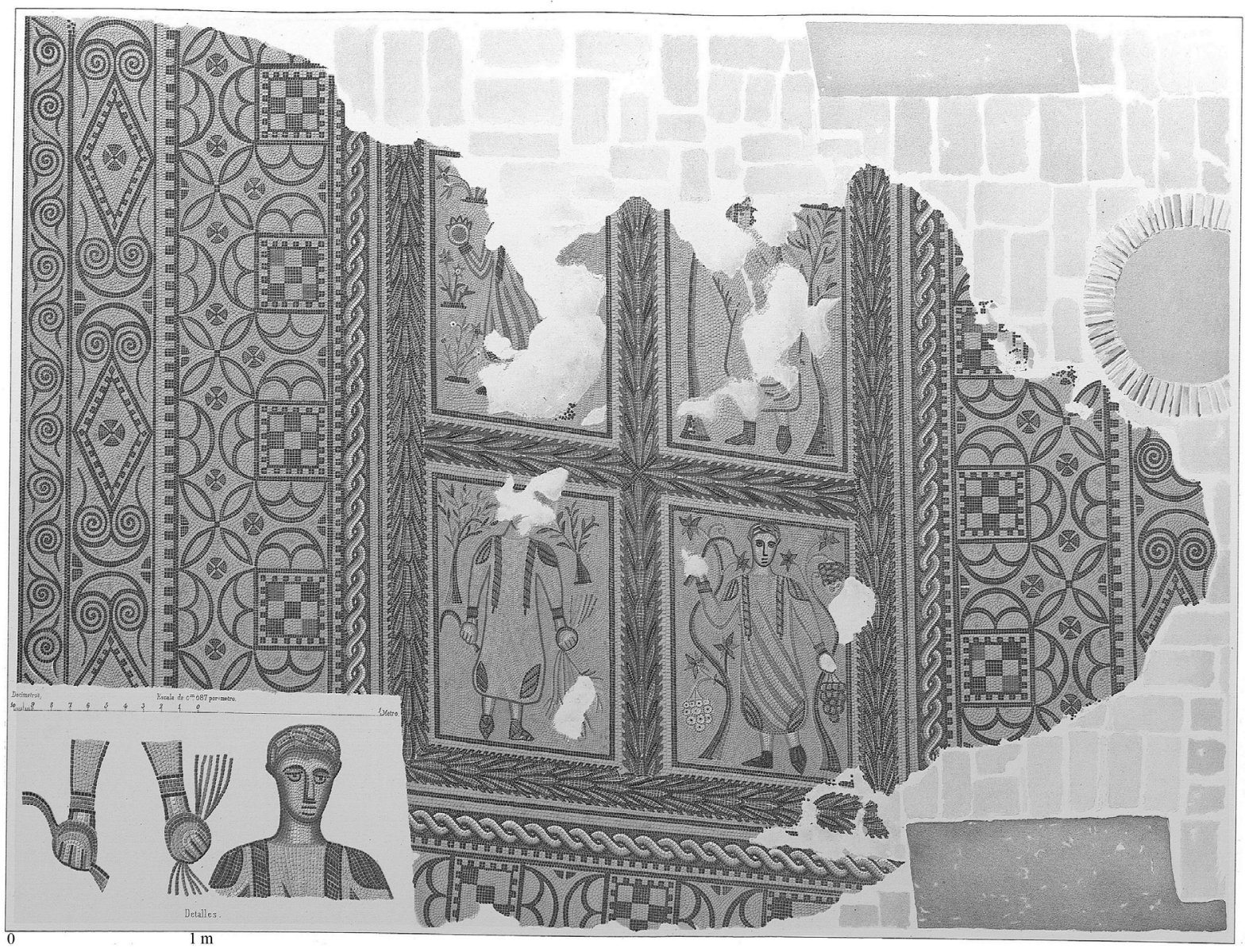

Figura 4. Pl. de la Compañía 5-9: grabado del mosaico recuperado (Amador de los Ríos y Amador de los Ríos 1879: s/n).

Esta última posibilidad parece detectarse en núcleos hispanorromanos como Iliberris, con varias villas periurbanas monumentalizadas en el siglo IV d.C. frente a un espacio in urbe ocupado por edificaciones peor conocidas, pero más modestas (Román Punzón 2005, Marín 2011, Rodríguez et al. 2013-2014: 498); y especialmente en Tarraco, donde la disgregación del tejido residencial intramuros en los siglos III-IV d.C. contrasta con la construcción de varias suntuosas domus del siglo IV d.C. (en ocasiones dotadas de balnea) descubiertas en el barrio portuario suburbano o a mayor distancia de la ciudad (López Vilar 2006: 240-241, Perich 2014b: 130 ss.).

A pesar de lo expuesto, en el espacio intramuros de Córdoba sí conocemos otras viviendas pertenecientes a individuos con un estatus socioeconómico notable. Es el caso de determinados inmuebles domésticos preexistentes, sometidos a reformas puntuales materializadas en la instalación de fuentes o de pavimentos musivos con sencillos motivos geométricos (Ventura y Carmona 1992: 207 y 209, López Rey 1995: 205-208, Soriano 2003: 450-453). A estas remodelaciones, fechadas en el siglo III d.C., hay que añadir otras peor conocidas que consistieron en una reorganización interna de determinadas viviendas mediante la construcción de muros de cierta entidad constructiva (a base de opus incertum o caementicium), que redujeron el tamaño de algunos ambientes (Ruiz Nieto 1999: 127-129, Valderrama 2007: 78 y 85-86). Estas reformas, datadas grosso modo en los siglos III-IV d.C., no deben interpretarse necesariamente en términos peyorativos, dado que la información procedente de otras viviendas hispanorromanas mejor documentadas apunta hacia un panorama más complejo. Es el caso de la astigitana "casa del Oscillum", puesto que en el último cuarto del siglo IV el tamaño de su patio se redujo prácticamente a la mitad al levantarse en este punto dos estancias (GarcíaDils 2015: 438-442). No obstante, "la construcción de 
una elegante fuente polilobulada en el patio reducido restante, rodeada por una pavimentación de losas de mármol blanco, evidencia que este proceso no puede calificarse como decadente" (García-Dils 2015: 490).

A estas viviendas cordobesas hay que sumar otras de nueva planta caracterizadas por el frecuente empleo de pavimentos musivos (de temática geométrica), su presumible articulación alrededor de patios (mal documentados), el uso recurrente de material reutilizado, y su especial concentración en la zona conocida hoy en día como "Altos de Santa Ana", a medio camino entre la parte alta y baja de la ciudad (Aparicio 1995: 230232, López López y Morena 1996: 113, García Vera 2003). Dentro de esta categoría, destacan las viviendas exhumadas en los siguientes solares:

- C/ Ángel de Saavedra 9: inmueble del siglo IV d.C. instalado en un antiguo conjunto cultual, lo que supuso el recrecimiento de determinados muros preexistentes, la construcción de otros y la cubrición de los antiguos pavimentos bajo otros nuevos de mosaico y signinum (Ventura 1991: 263-264).

- C/ María Cristina 4 (fig. 5a): domus de los siglos III-IV d.C. compuesta por, al menos, ocho espacios que incluyen un balneum y un posible atrio (Criado 2010: 21-24).

- C/ María Cristina 7 (fig. 5b): una o varias unidades domésticas de la segunda mitad del siglo IV d.C. levantadas en la plaza y en uno de los pórticos de un antiguo complejo religioso. Hasta la fecha conocemos varios ambientes (en algún caso con suelo de opus signinum) entre los que destaca un patio cuadrangular de unos 4 por $4 \mathrm{~m}$ (Jiménez et al. 1996: 125-127).

- Pl. Ramón y Cajal 2: varios ambientes (dos de ellos decorados con pavimentos musivos) pertenecientes a una edificación doméstica de los siglos III-IV d.C. cuya construcción supuso la ocupación parcial de un eje viario (Martín 2012: 101 ss.).

Desde un punto de vista topográfico, destaca la instalación de algunas de dichas viviendas (c/ Ángel de Saavedra 9 y c/ María Cristina 7) en antiguos complejos públicos por entonces ya abandonados. Nos encontramos ante un fenómeno no exclusivo de Córdoba, puesto que en otras ciudades están empezando a identificarse viviendas de cierta entidad arquitectónica y decorativa levantadas en emplazamientos parecidos (Diarte 2012: 250 y 254-255). Es el caso de Barcino, con una domus aristocrática del siglo IV d.C. ubicada en un edificio que parece corresponderse con la antigua curia forense (Beltrán de Heredia 2015: 135-138);
Uxama, donde una amplia plaza porticada (quizás un primigenio foro) fue ocupada por una domus con mosaicos de finales del siglo III o inicios del IV d.C. (García Merino 2007: 208 y 211), y ya a escala suprapeninsular, Cirene, al haberse individualizado varias viviendas de finales del siglo IV d.C. (en algunos casos articuladas alrededor de un peristilo) construidas en la antigua ágora (Ellis 1998: 237). Tales hallazgos permiten matizar la extendida hipótesis tradicional que describía siempre "the late antique occupants of disused public buildings in derogatory terms, as poor or squatters" (Ellis 1998: 237).

En el espacio intramuros de Córdoba también ha podido individualizarse una dinámica consistente en la destrucción de varias viviendas a lo largo de los siglos III y IV d.C. (Moreno Rosa 1990), y más concretamente entre el siglo III y finales del siglo III - inicios del IV d.C. (López López y Morena 1996: 108, Morena y Botella 2001: 235-236, Soriano 2003: 452 y 453, Vargas 2005: 171, Moreno Almenara y Murillo 2006: 100, Moreno Almenara 2018 e.p.). La inutilización de diversas edificaciones domésticas en un marco temporal no excesivamente amplio es un fenómeno que también ha podido rastrearse en otras ciudades. En Hispania tenemos Valentia, donde a finales del siglo III d.C. y por causas no del todo conocidas, tuvieron lugar varios episodios violentos (en forma de incendios) a los que no escaparon determinados inmuebles residenciales ( $\mathrm{Ri}$ bera y Jiménez 2012: 104). A una escala ya suprapeninsular, destaca la información procedente de Rimini o Sarsina (Italia), puesto que la destrucción súbita de varias viviendas se ha puesto en relación con las correrías de los alamanes entre 254 y 271 d.C. (Ortalli 2003: 99).

En el caso de Córdoba, en los últimos años ha cobrado peso la idea de que la ciudad sufriese los efectos de un terremoto datado hacia los años 50-60 del siglo III d.C. y que ocasionó la inutilización del teatro y del acueducto Aqua Augusta Vetus (Ventura y Pizarro 2010: 198-199, Morín et al. 2014, Ruiz Bueno 2017). Ante tal contexto, determinadas voces han planteado la posibilidad de que la destrucción violenta y súbita de las estructuras domésticas halladas en puntos como c/ Ambrosio de Morales 20 (Soriano 2003: 454) y c/ Ramírez de las Casas Deza 10-12 (Moreno Almenara 2018 e.p.) se pueda deber al citado seísmo. Aunque se trata de una sugerente hipótesis, la ausencia de estudios arqueosismológicos en profundidad y las discordancias cronológicas (la fecha de amortización no es bien conocida, o no coincide con la del posible terremoto), nos impide confirmar dicho nexo (Ruiz Bueno 2017). Por el momento no podemos dar una 


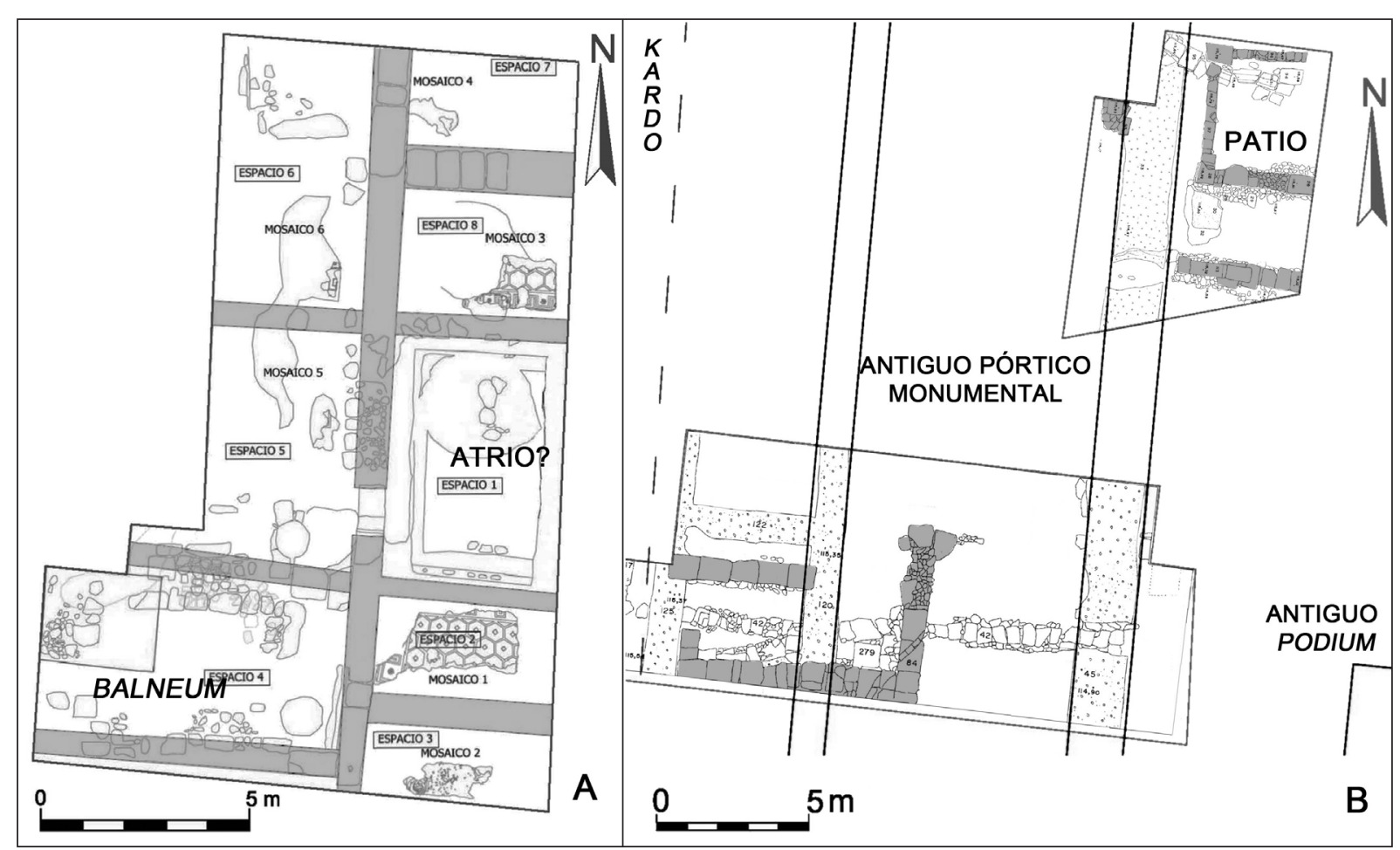

Figura 5. A: c/ María Cristina 4: planta de la domus de los siglos III-IV d.C. Modificado a partir de Criado 2010: plano 9. B: c/ María Cristina 7: planta de las estructuras domésticas de la segunda mitad del siglo IV d.C. Modificado a partir de Jiménez et al. 1996: fig. 2,4 y 5 .

explicación convincente a unas destrucciones cuyo alcance exacto se desconoce.

En cualquier caso, la inutilización del teatro debió de convertir al edificio y sus alrededores en una zona de marcado carácter productivo y artesanal, donde proliferaron no solo los talleres y las labores de saqueo (López López 1998: 281 y 334, Monterroso 2002: 147 ss., Soriano 2003: 452-454), sino también algunas estructuras domésticas más humildes caracterizadas por la presencia de pavimentos sencillos (terrizos, de cal y adobe) y por el empleo de materiales pétreos reutilizados (Carrasco 2001: 108-109, Monterroso 2002: 157), pero también de otros perecederos como la madera (Castro y Carrillo 2005: 355).

\subsection{El espacio extramuros}

Si damos el salto al espacio extramuros (fig. 1), la dinámica más reseñable fue el lento, pero inexorable despoblamiento de los barrios suburbanos cordobeses a partir del segundo cuarto del siglo III d.C. (Molina y Sánchez 2002-2003: 358-359, Cánovas 2010: 426-427,
Vargas 2010: 457-458, Ruiz Bueno 2016: 235-239). De hecho, más allá de las últimas décadas de la tercera centuria tan solo conocemos varios inmuebles identificados en sectores muy concretos tanto del barrio extramuros septentrional, donde la información se limita a algunas estructuras domésticas y/o de almacenaje en uso hasta el siglo IV d.C. (Ventura 1998: 11-12, 22 y 36), como sobre todo del barrio oriental, al haberse exhumado varios mosaicos de finales del siglo III - inicios del IV d.C. destinados a ornamentar domus construidas o reformadas en estos momentos (Moreno González 1996: 206, 213-215, 233 у 236)

El abandono progresivo de los barrios extramuros es un fenómeno rastreable también a escala peninsular (Perich 2014a: 129 y 133) y que no se puede achacar necesariamente a motivaciones de carácter defensivo. De hecho, el destino de dichos barrios contrasta con la evolución de otros establecimientos residenciales de alto nivel ubicados a una mayor distancia de las ciudades. Si nos centramos en Córdoba, el registro arqueológico atestigua no solo la ausencia de propiedades (suburbanas y periurbanas) claramente abandonadas en los siglos III-IV d.C., sino su monumentalización ocasional 
e incluso, la construcción de algunos conjuntos de nueva planta caracterizados por su rica decoración musivaria y por disponer de espacios de representación rematados en ábsides. Dentro de esta última categoría, el ejemplo mejor documentado hasta la fecha es el localizado en c/ Algarrobo 4, donde salió a la luz un conjunto construido a finales del siglo III-inicios del IV d.C. y del que conocemos dos sectores. Del más meridional hay evidencias de varias estancias (un triclinium rematado en ábside, un cubiculum, un tablinum y una piscina dotada quizás de ninfeo) distribuidas en torno a un patio cuadrangular provisto de una fuente ortogonal. Del más septentrional (fig. 6) se conocen cinco espacios articulados alrededor de un patio porticado y cuadrangular, donde se instaló una fuente o juego de aguas (Penco 2005: 20 ss., Salinas 2005: 37 ss., Perich 2014a: 129-133, Vaquerizo 2014: 24).

Más exigua es la información acerca de otro posible establecimiento doméstico lujoso situado a poniente de la urbe, donde fue descubierto un acueducto de finales del siglo III-inicios del IV d.C. ("acueducto de la Huerta de Santa Isabel Oeste"), destinado al abastecimiento de una gran propiedad periurbana (incluyendo un probable inmueble termal privado) cuya ubicación exacta es controvertida (Ventura y Pizarro 2010: 200, León et al. 2014: 158).

A dichos ejemplos hay que sumar el polémico complejo bajoimperial de Cercadilla, interpretado por J. Arce (2010: 409) como una villa de finales del siglo III-inicios del IV perteneciente a un personaje de alto rango, mientras que otras voces abogan por interpretarlo como un palacio imperial (Hidalgo 2014) o como la sede del vicarius hispanarium (Vaquerizo y Murillo 2010: 493 ss.) entre otras opciones, por lo que el debate acerca de su exacta funcionalidad (pública, semipública o privada) sigue abierto.

\section{SIGLOS V-VII d.C.}

La llegada de la quinta centuria supuso una etapa clave en la evolución de la arquitectura doméstica urbana. A lo largo y ancho del vetusto imperio han podido rastrearse diversas dinámicas que caracterizaron al marco temporal comprendido entre los siglos V y VII d.C.

Entre las novedades que trajo consigo el siglo $\mathrm{V}$ d.C., destaca el paulatino abandono de los peristilos como centro compositivo y articulador de las viviendas aristocráticas, con el consecuente hundimiento en el número de domus de esta tipología erigidas en la quinta centuria (Saradi 1998: 28, Brogiolo 2011: 75).
Dicho proceso culminó hacia la segunda mitad del siglo VI d.C., cuando en la ciudad griega de Argos fue construido un inmueble ("house of the Falconer") que constituye uno de los últimos ejemplos bien conocidos de este tipo de residencia señorial (Baldini 2001: 71 y 145). La desaparición progresiva de las domus de peristilo fue coetánea a la entrada en escena de un nuevo modelo de residencia aristocrática. Se trata de inmuebles compactos, de planta rectangular, desarrollados en varias alturas (las superiores destinadas a espacios representativos y de aparato), que suelen prescindir de un espacio abierto central y que tienden a emplazarse en ubicaciones relativamente elevadas (Santangeli 2011: 30-32, 75 ss. y 134-137; Mar y Perich 2014: 444-447, Perich 2014a: 169, 175, 228-233 y 251).

La combinación de ambas dinámicas supuso la desocupación o el abandono (por lo general no traumático) de numerosas domus. Estos inmuebles fueron frecuentemente reconvertidos en casas de vecinos habitadas por individuos de baja extracción social. Tal cambio en el tipo de morador implicó una serie de transformaciones como la eliminación de los pórticos del atrio y del peristilo; la supresión de buena parte de los elementos arquitectónicos y decorativos del patio (salvo los pozos de agua limpia); la reestructuración de los accesos interiores a las dependencias; la compartimentación de determinadas estancias o la ampliación de otras; la conversión de las distintas partes de las domus en áreas polifuncionales; el empleo generalizado de pavimentos terrizos, o el abandono de los antiguos balnea (Alba 2005: 132-137, Arce et al. 2007: 323, Perich 2014a: 249).

Las antiguas domus reconvertidas en casas de vecinos, pero también otros edificios de nueva planta erigidos sobre todo tipo de emplazamientos, pasaron a convertirse en el lugar de residencia de buena parte de la población urbana. En ambos casos consistieron en unidades domésticas de pequeñas dimensiones, de planta cuadrangular o rectangular, con pocas divisiones internas (entre uno y tres departamentos de media), con pavimentos sencillos (de tierra batida o cerámica), donde la vida giró en torno a un hogar a base de arcilla endurecida y en cuyo interior (o entorno inmediato) se llevaron a cabo actividades productivas e incluso, de carácter funerario (Ramallo 2000: 368 y 380-382, Vizcaíno 2009: 380 ss., Santangeli 2011: 129-134, Gutiérrez 2012: 143 ss., Perich 2014a: 167). Pese a que las construcciones de nueva planta recurrieron eminentemente a técnicas edilicias mixtas, un número creciente de ellas se sirvió de materiales perecederos como la madera. Este tipo de arquitectura está bien documentada 


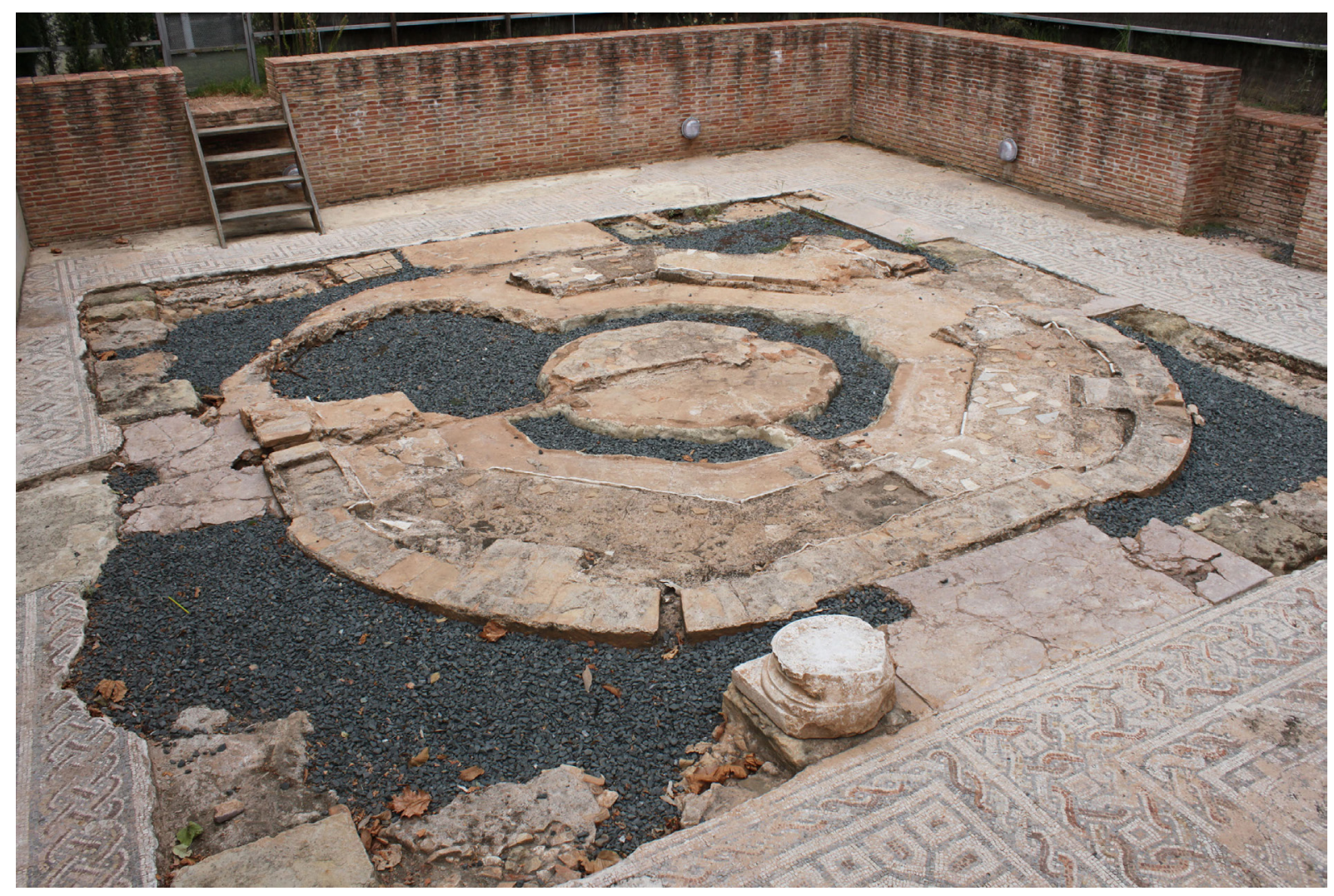

Figura 6. C/ Algarrobo 4: vista actual del sector septentrional del complejo residencial suburbano. Fotografía del autor.

en algunas ciudades italianas (Santangeli 2011: 33-66), aunque no tanto en contextos urbanos hispanorromanos (Azkarate y Quirós 2001: 40-41).

En definitiva, es evidente que la arquitectura doméstica urbana se caracterizó desde el siglo V d.C. en adelante por la coexistencia en el espacio de antiguas domus aristocráticas reconvertidas en viviendas comunitarias, construcciones ex novo caracterizadas por su heterogénea ubicación, planta y técnica edilicia y, por último, un reducido número de inmuebles compactos donde residieron las clases más privilegiadas.

Si damos el salto a Corduba, la documentación arqueológica actualmente disponible ha posibilitado la identificación de diversas dinámicas en el espacio tanto intramuros, como extramuros.

\subsection{El espacio intramuros}

El análisis conjunto de las evidencias arqueológicas domésticas in urbe (fig. 3) nos ha permitido rastrear el presumible abandono de la mayor parte de las viviendas preexistentes. Si a finales del siglo IV d.C. tenemos constancia de unos dieciocho emplazamientos ocupados por estructuras domésticas de diversa índole (en su mayor parte pertenecientes a individuos con cierto status socioeconómico), a finales del siglo V-inicios del VI d.C., dicha muestra se reduce a apenas tres o cuatro (López Rey 1995: 205, Carrasco 2001: 108-109, Valderrama 2007: 85-90, Martín 2012: 114). Por el contrario, el resto de los inmuebles quedaron presumiblemente inutilizados (Bermúdez et al. 1991: 57, Ventura 1991: 263, Ventura y Carmona 1992: 221, Ruiz Nieto 1994, 1999: 130, Aparicio 1995: 230-232, Jiménez et al. 1996: 127, López López y Morena 1996: 100 y 103, Montejo 1998: 33, 2006: 11 y 32, Molina 2002: 36-37 y 45, Pérez Navarro 2003: 68).

Desafortunadamente, este aparente proceso de abandono no se conoce con la precisión deseada debido a factores como la antigüedad de algunas intervenciones, la reducida superficie exhumada y las alteraciones post-deposicionales. Tampoco podemos olvidar el frecuente empleo del monetario como único elemento de datación (pese al prolongado período de circulación de las monedas del siglo IV d.C.), con los problemas que ello conlleva (Marot 2000-2001: 134-135). Como 
resultado, en muchos casos ignoramos la fecha exacta de abandono de las viviendas y si, en realidad, lo que tuvo lugar fue su reconversión en inmuebles plurifamilares y de carácter más modesto. Esta última dinámica es bien conocida en Astigi (García-Dils 2015: 442-443 y 492), Augusta Emerita (Alba 2005: 132-137 y 145146) o Barcino (Cortes 2011: 41-42 y 55, Beltrán de Heredia 2013: 49-51), por citar solo algunos ejemplos a escala peninsular.

Pese a que "los hogares son la prueba más fiable para reconocer el número de viviendas en que se subdividió cada domus" (Alba 2005: 137), la metodología y/o antigüedad de las excavaciones cordobesas ha provocado que tan solo hayamos podido identificar un único hogar in urbe de los siglos VI-VII d.C. (Monterroso y Cepillo 2002: 163). Por si fuera poco, la documentación arqueológica procede normalmente de un sector concreto de cada vivienda (no existe ninguna exhumada en su totalidad), lo que impide precisar la evolución de los inmuebles en su conjunto. Asimismo, no descartamos que algunos derrumbes mencionados como tales en las memorias de excavación, sean en realidad niveles de relleno destinados a ocultar los pavimentos primigenios con el fin de favorecer un nuevo uso. Recordemos que la reconversión de antiguas domus unifamiliares en casas de vecinos implicó a menudo la ocultación de los primitivos suelos bajo niveles de cascotes o de tierra, tal y como se ha podido identificar en inmuebles como la "casa de las Figlinas" de Hispalis (González 2011: 386).

A la vista de lo expuesto, la transformación de las antiguas domus en viviendas plurifamiliares sigue siendo un fenómeno mal conocido en el antiguo caput provinciae bético y que solo se puede presuponer con cierta seguridad en algunas domus caracterizadas por su prolongado uso (hasta las postrimerías de la Antigüedad Tardía) y por la paulatina reocupación y reutilización de las estructuras precedentes (López Rey 1995: 205-208, Martín 2012: 114). Por fortuna, disponemos de más datos acerca de otras viviendas de nueva planta levantadas en diversos emplazamientos y que, si nos atenemos a su fisonomía (dimensiones, técnicas constructivas, etc.), parecen responder a una arquitectura doméstica de carácter popular. Destacan las estructuras documentadas en los siguientes tres solares:

- C/ Duque de Hornachuelos 8 (fig. 7a): antiguo establecimiento termal público o semipúblico que fue ocupado en el siglo V d.C. por varios ambientes domésticos, lo que supuso la reutilización de algunos paramentos preexistentes y la construcción de otros nuevos (Ruiz Nieto 2003: 21 ss. y 81).
— Pl. de Jerónimo Páez 7 (fig. 7b): barrio instalado en el antiguo teatro (tras una labor previa de regularización y aterrazamiento del terreno) y del que conocemos una vivienda de la primera mitad del siglo VII d.C. compuesta por varias estancias (Monterroso y Cepillo 2002: 163-166).

- C/ Ramírez de las Casas-Deza 13: vivienda del siglo V d.C. que ocupó el pórtico septentrional de un decumanus y un inmueble adyacente, lo que supuso el recrecimiento de algunos paramentos, la cubrición del pavimento del pórtico bajo esteras vegetales y la reducción de anchura de un antiguo vano (Hidalgo 1993: 99-101 y 109).

En los tres casos se trata de construcciones domésticas instaladas en antiguos espacios o edificios públicos. Dicha ocupación, también identificada a lo largo de los siglos V-VII d.C. en núcleos como Augusta Emerita (Alba 2007: 175-176, 2011: 532 ss.), Carthago Nova (Vizcaíno 2009: 387 ss.), Tarraco (Pérez Martínez 2012: 128-133, Macías 2013: 129-130) o Valentia (Ribera y Rosselló 2009: 199), no resulta sorprendente. En este sentido, a partir del siglo V d.C. se intensificó la privatización de vías y de antiguas construcciones públicas ya abandonadas. Tal invasión fue un fenómeno regulado en mayor o menor medida por las autoridades, quienes frecuentemente promovieron tanto la urbanización de antiguos edificios públicos (con el fin de favorecer su habitabilidad), como su arrendamiento para usos privados (Ellis 1998: 234 ss., Saliou 2005: 213 ss., Diarte 2012: 255).

Aun cuando el espacio intramuros de Corduba debió de estar ocupado en gran medida por construcciones domésticas de carácter popular, el registro arqueológico también atestigua varios inmuebles vinculados a la élite y que pudieron haber tenido un carácter residencial. En primer lugar tenemos un grupo de edificios caracterizados por el empleo de muros de considerable potencia (60-70 $\mathrm{cm}$ de media) a base de mampuestos y sillares reutilizados, y de los que apenas tenemos huellas de pavimentos, revestimientos y techumbres (Aparicio 1996, Moreno Almenara y González 2001: 166-167, Ruiz Nieto 2003: 34 ss. y 82-83). Dos de ellos (c/ Duque de Hornachuelos 8 y pl. de Maimónides 1) han sido datados en los siglos VI-VII d.C., mientras que el tercero (c/ Góngora 8), presenta una datación más genérica (siglos IV-VII d.C.). Si tenemos en cuenta el carácter compacto de dichos inmuebles, la planta conocida (fig. 8 y 9a), la amplitud de las estancias, la presumible existencia de un segundo piso y la ausencia de pavimentos de opus sectile o tesellatum en las plantas 


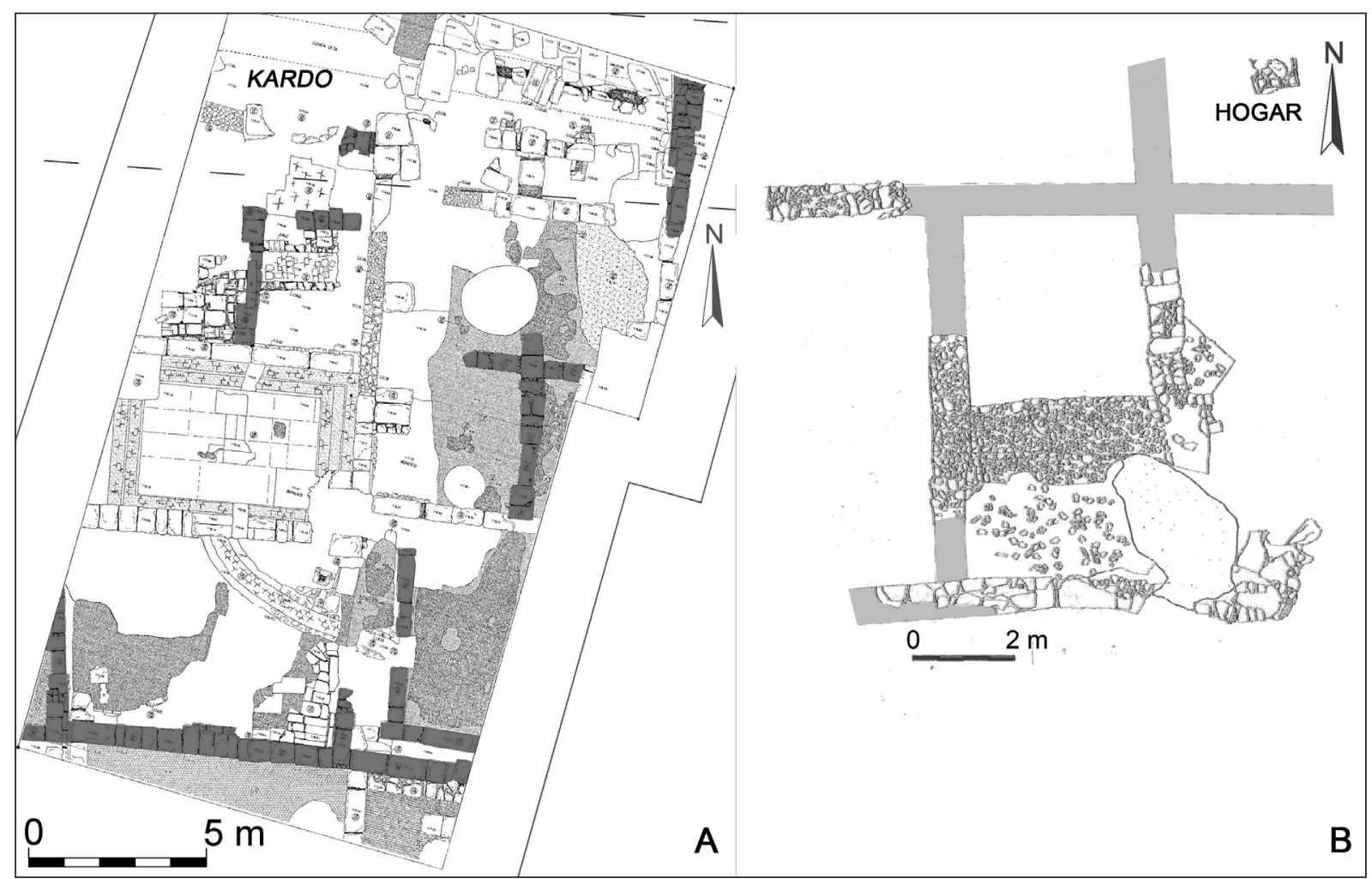

Figura 7. A: c/ Duque de Hornachuelos 8: estructuras domésticas del siglo V d.C. levantadas en un antiguo complejo termal (con indicación de los paramentos construidos o reutilizados en estos momentos). Modificado a partir de Ruiz Nieto 2003: plano 9. B: Pl. de Jerónimo Páez 7: planta del inmueble doméstico de la primera mitad del siglo VII d.C. Modificado a partir de Monterroso y Cepillo 2002: fig. 3.

inferiores (las únicas conocidas), una de las hipótesis que barajamos es que se trate de inmuebles residenciales vinculados a las clases dirigentes, tal y como se ha documentado recientemente en núcleos como Barcino (Beltrán de Heredia 2013: 48 y 52) y, con más dudas, en Augusta Emerita (Alba 2005: 146, 2007: 178, Ayerbe 2009: 72-73). No obstante, las características que presentan los edificios cordobeses también han podido rastrearse en otros inmuebles vinculados a la administración, como son los posibles palatia de los comites $\mathrm{ci}$ vitatis de Barcino y Gerunda (Nolla y Palahí 2010: 21, Beltrán de Heredia 2014: 471-472), por lo que no podemos descartar completamente que tuviesen un uso público o semipúblico.

Las dudas acerca de la exacta funcionalidad de dichos inmuebles son también extensibles a otra construcción cordobesa in urbe descubierta en las inmediaciones del complejo episcopal tardoantiguo (fig. 3). En c/ Rey Heredia 20 salió a la luz un edificio cuyos muros (con zócalo de opus quadratum y alzado de tapial) delimitaban ambientes con pavimentos de opus signinum o tesellatum y techumbres de tegulae (Marfil 1996a, 1996b y 1996c, Penco 2000 y 2002). Más difícil es determinar la planta exacta del inmueble, así como la exacta conexión entre sí de los distintos paramentos y suelos exhumados (Caballero et al. 2007: 13-14, Utrero 2009: 143-144, Vizcaíno 2009: 157 y 451, Ruiz Bueno y González 2017: 254-260).

Entre los rasgos más destacados (y polémicos) del edificio de c/ Rey Heredia 20, tenemos un mosaico polícromo que se ha venido datando en el siglo VI d.C. y que ornamentó una habitación (de unos 4,70 m de ancho por 5,25 de largo) cuya exacta funcionalidad es discutida. Aunque el exhaustivo estudio del pavimento (fig. 9b) deja pocas dudas acerca de su simbología cristiana y de su influencia bizantina (Penco 2000 y 2002), más difícil es afirmar o descartar si el citado suelo perteneció a una estancia sacra o profana. La presencia de elementos vegetales, aves y recipientes en el interior de círculos grandes y pequeños, tangentes y enlazados, o en los octógonos resultantes de dicho esquema, es un fenómeno frecuente en los mosaicos de determinadas 


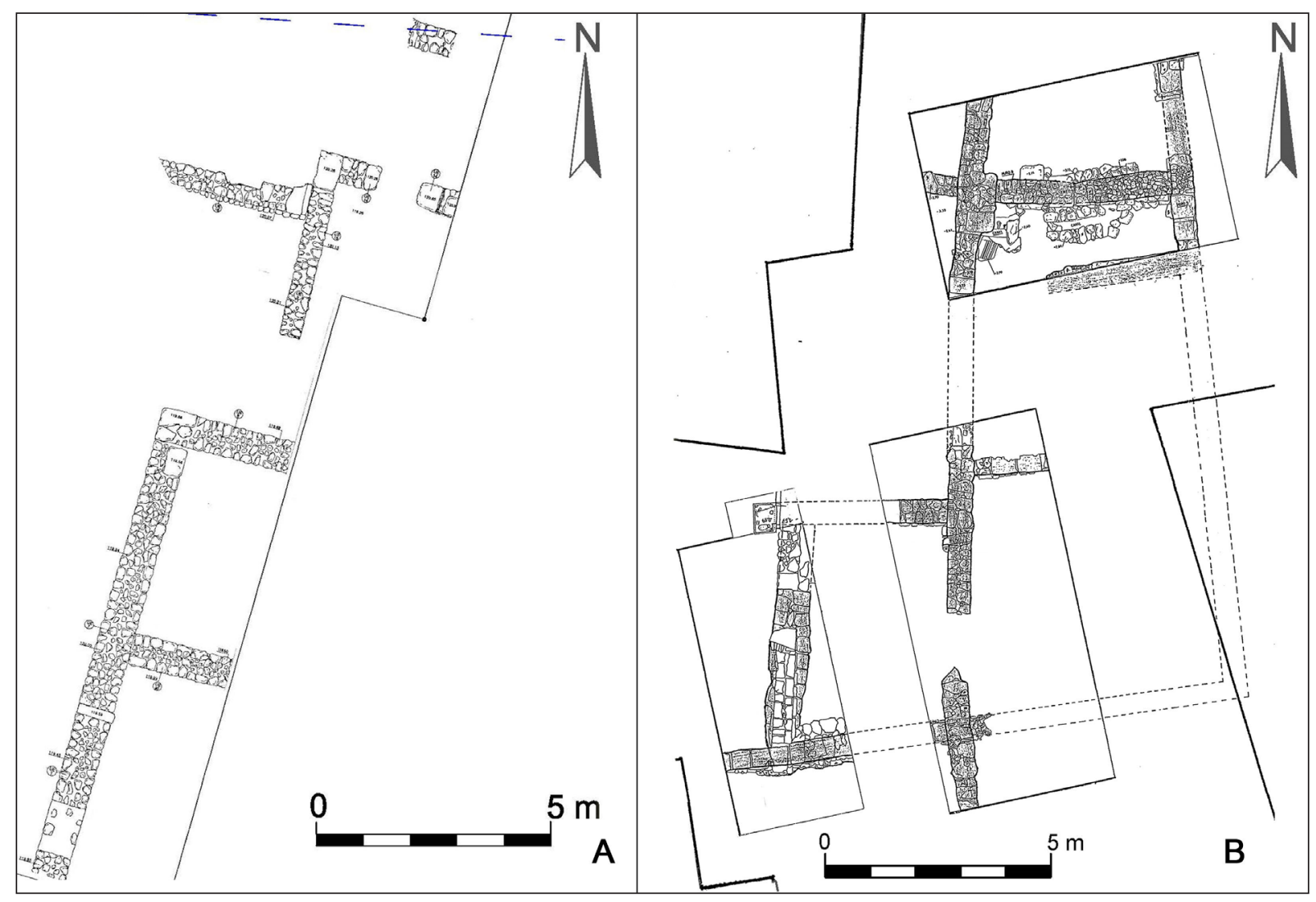

Figura 8. A: c/ Duque de Hornachuelos 8: planta del edificio de los siglos VI-VII d.C. Modificado a partir de Ruiz Nieto 2003: plano 8. B: c/ Góngora 8: planta (parcial) del inmueble tardoantiguo (ss. IV-VII d.C.). Modificado a partir de Aparicio 1996: plano 18.

iglesias del siglo VI d.C. (Penco 2000: 249-250, 2002: 13-14). No obstante, también documentamos su uso en construcciones profanas como es el caso de un mosaico de finales del siglo III o inicios del IV d.C. perteneciente a una rica domus de Roma (Baldasarri 2011: $49-50$ y 58 ss.), o del pavimento de mediados-segunda mitad del siglo V d.C. localizado en la ciudad griega de Cos, y "non attribuibili a edifici religiosi" (De Matteis 2004: 215).

Como resultado, en c/ Rey Heredia 20 no podemos precisar la funcionalidad exacta ni de la habitación ornamentada mediante el mosaico polícromo, ni de la construcción de la que formó parte, ya que pudo tratarse de un edificio religioso (no necesariamente una iglesia) o bien de una residencia de un alto cargo eclesiástico o de un aristócrata laico, entre otras opciones (Ruiz Bueno y González 2017). Esta última opción no está exenta de problemas, dada la compleja evolución de la arquitectura residencial aristocrática a lo largo de los siglos V y VI d.C. En el supuesto caso de que las estructuras cordobesas pertenezcan a una edificación doméstica, es factible que nos encontremos ante una domus cuyos espacios de representación se emplazaron en la planta baja, al estilo de las antiguas casas unifamiliares aristocráticas. Dicha hipótesis presenta algunos obstáculos, dado que en Hispania no conocemos ni una sola domus propiamente dicha que fuese construida o monumentalizada en la sexta centuria. Por el contrario para la segunda mitad del siglo $\mathrm{V}$ d.C. sí contamos con algunos ejemplos aislados caracterizados por la instalación tanto de mosaicos ("casa de Cupidos" de Complutum, Rascón y Sánchez 2015: 211) como de espacios de representación con stibadia ("casa del Sigma" de Hispalis, García Vargas 2012: 904). El vacío del siglo VI d.C. es especialmente llamativo en el mundo urbano de la Spania bizantina Septem (Vizcaíno 2009: 387), puesto que en otras urbes mediterráneas bajo control bizantino hay evidencias de viviendas decoradas con mosaicos fechados en el siglo VI d.C., cuando tuvo lugar su construcción o reforma (Baldini 2001: 133, 138, 142, 145 y 214). 
Figura 9. A: Pl. de Maimónides 1: planta del inmueble de los siglos VI-VII d.C. (Moreno Almenara y González 2001: fig. 3). B: c/ Rey Heredia 20: vista del mosaico polícromo (Penco 2000: fig. 1).

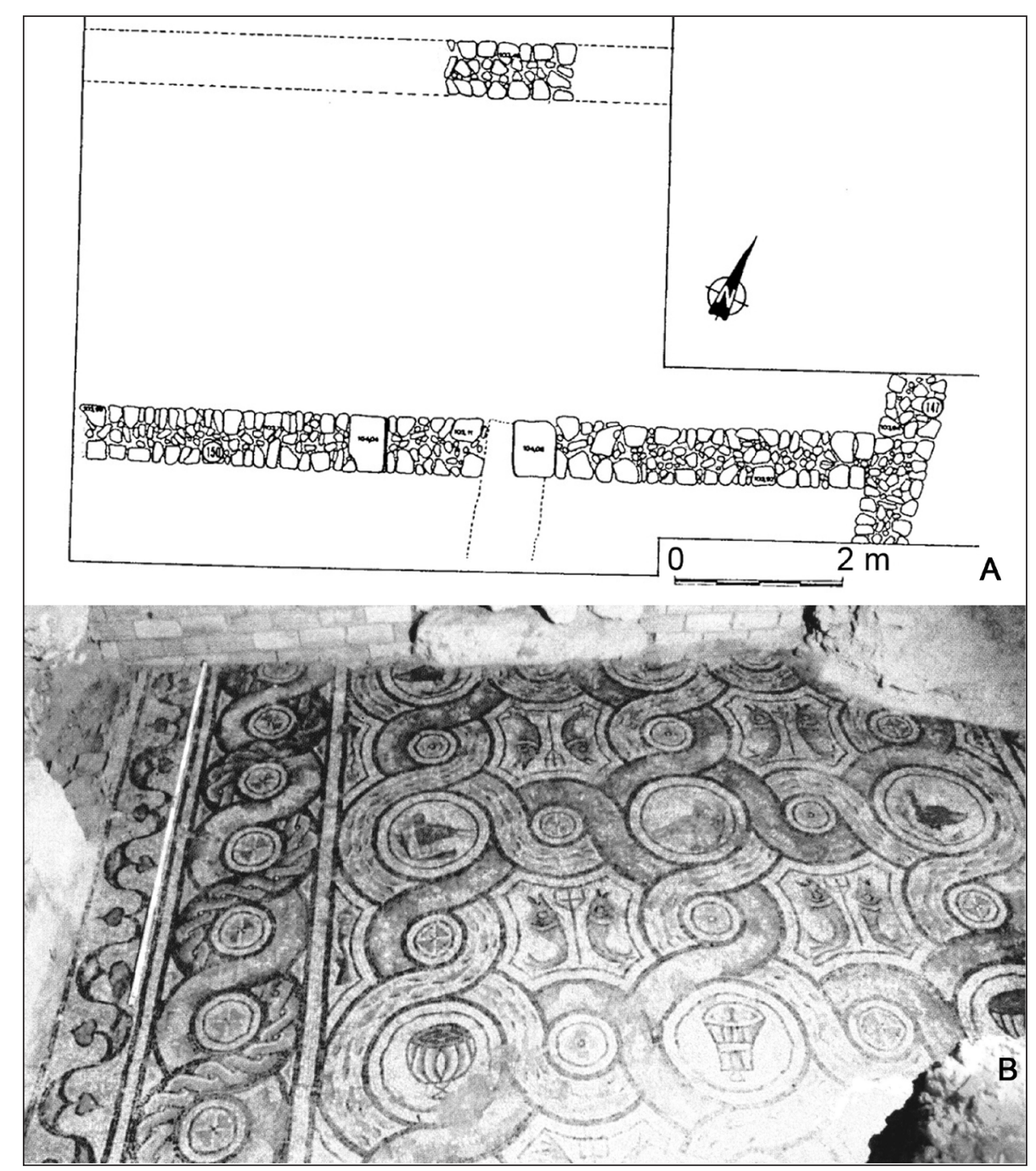

\subsection{El espacio extramuros}

Por último, y al igual que en etapas anteriores, el suburbio cordubense debió de estar ocupado por estructuras domésticas de diversa índole pero cuya detección resulta esquiva. Pese al abandono de un par de suntuosos establecimientos residenciales suburbanos hacia el tránsito del siglo IV al V d.C. (Salinas 2005: 51-52, Ortiz 2011: 273-274), otras propiedades domésticas y/o productivas debieron de estar en uso hasta, al menos, inicios del siglo VIII d.C. Dicha posibilidad está fundamentada en varias evidencias indirectas (mantenimiento de la infraestructura hidráulica, construcción de dependencias productivas, testimonios funerarios, fuentes escritas andalusíes, etc.) que apuntan en dicha dirección (Murillo et al. 2010: 516, López Cuevas 2013: 244-245, León et al. 2014). Especialmente significativa es la información proporcionada por la historiografía árabe, ya que menciona una serie de edificios preislámicos que, tras la conquista, recibieron el nombre de balāt (termino derivado de palatium). Situados a las afueras de la ciudad, su ubicación exacta no ha podido ser determinada. De hecho, tan solo sabemos que el Balāt Mugịt se situaba en las inmediaciones del ángulo suroeste de la muralla, mientras que el Balāt al-Hurr estaba a levante de la ciudad (López Cuevas 2013: 244-245).

A la espera de futuras excavaciones arqueológicas que nos permitan conocer la fisonomía de estos establecimientos extramuros (especialmente de su área residencial), tenemos que limitarnos a la información procedente de otras ciudades como Augusta Emerita (Feijoo 2000: 339-347), Tarraco (Mar y Guidi 2010: 177-179, Mar y Perich 2014: 444) y Toletum (Rojas y 
Gómez 2009: 77). En ellas han sido descubiertos varios complejos residenciales suburbanos de los siglos VI-VII d.C. que contaban con zonas productivas, balnea privados, e incluso, espacios de representación con planta basilical.

Además de estas construcciones vinculadas a las clases dirigentes, el espacio extramuros de Corduba acogió hacia los siglos VI-VII d.C. diversas aglomeraciones suburbanas surgidas, al parecer, en el entorno de los principales loca sacra. Conocidas gracias a varios escritores árabes, su detección arqueológica resulta problemática, puesto que apenas disponemos de huellas materiales (Acién y Vallejo 1998: 110, Sánchez 2006: 275-276). Entre las excepciones tenemos determinadas estructuras (varios muros y pavimentos, además de un horno) que evidencian la reocupación doméstica del vetusto criptopórtico del complejo bajoimperial de Cercadilla (Fuertes e Hidalgo 2010: 168-170). Asimismo, no descartamos que el suburbium cordubense albergase inmuebles aislados de planta sencilla, al estilo de los localizados en los últimos años en $\mathrm{Au}$ gusta Emerita, donde han sido individualizadas diversas edificaciones con una, dos o más estancias, accesos independientes orientados a posibles espacios cercados y otras dependencias vecinas (Alba 2005: 142).

\section{CONCLUSIONES}

Nuestro nivel de conocimiento sobre la arquitectura doméstica de Corduba sigue siendo parco, limitado y desigual en comparación con otras ciudades hispanorromanas de similar importancia y rango administrativo. Dicha problemática es especialmente evidente en el espacio in urbe, que en su mayor parte debió de estar ocupado por viviendas de distinta categoría, extensión y entidad. Aun cuando los problemas que presenta el registro arqueológico cordobés son extensibles a otras ciudades históricas de la península ibérica, el espacio intramuros de Córdoba no ha sido objeto de excavaciones arqueológicas de gran extensión, al estilo de las llevadas a cabo en el barrio de Morería de Mérida $\left(12.000 \mathrm{~m}^{2}\right)$, la plaza de España de Écija $\left(4.000 \mathrm{~m}^{2}\right)$ y la plaza de la Encarnación de Sevilla $\left(6.000 \mathrm{~m}^{2}\right)$. Tales intervenciones han permitido conocer con precisión la transformación de amplias áreas residenciales romanas a lo largo de la Antigüedad Tardía, al haber sacado a la luz diversas estructuras domésticas (no solo domus, sino también edificios residenciales más modestos) cuya planta y evolución se conocen con bastante precisión.
A la espera de futuras excavaciones arqueológicas similares en el antiguo caput provinciae bético, la documentación procede en gran medida de inmuebles residenciales exhumados de forma muy parcial, por lo que no hemos podido profundizar en cuestiones tipológicas o de organización, circulación y distribución interna. Pese a dicho obstáculo, por el momento insalvable, la revisión y el estudio crítico de antiguos hallazgos y de algunas intervenciones arqueológicas recientes, nos ha permitido rastrear o presuponer determinadas dinámicas en las que debió de participar la arquitectura doméstica cordubense.

En primer lugar podemos mencionar la elevada demanda de espacio habitable entre mediados del siglo II y comienzos del III d.C., cuando no solo los barrios suburbanos que rodeaban a la ciudad alcanzaron su máxima extensión espacial (a costa de estructuras con una funcionalidad previa distinta), sino que en la superficie in urbe se asistió tanto a la privatización de determinados ejes viarios, como a la urbanización de solares hasta entonces desocupados. Esta fase expansiva se frenó en seco a lo largo de la tercera centuria, momento caracterizado por un paulatino abandono de los distintos barrios extramuros que, en principio, no parece haber implicado una densificación generalizada del espacio intramuros. En este sentido, la instalación de viviendas en ejes viarios o en antiguos edificios públicos monumentales contrasta con la presumible inutilización de un considerable número de viviendas en dos marcos temporales coincidentes, grosso modo, con el siglo III d.C. y con el siglo V d.C. En ambos casos no hemos podido dar una explicación convincente a unos episodios cuyo alcance exacto desconocemos. De hecho, no descartamos que la desatención de determinadas domus a lo largo del siglo V d.C. refleje, en realidad, su transformación en casas de vecinos habitadas por individuos de inferior condición socioeconómica. Tal posibilidad también puede sugerirse en algunas domus habitadas hasta fechas muy avanzadas (siglos VI-VII d.C.) y que se caracterizaron por la continua reocupación y reutilización de las estructuras precedentes.

Otro fenómeno a tener en cuenta fue la monumentalización de la arquitectura doméstica vinculada a la aristocracia más acomodada. En Corduba, la muestra de tales edificaciones es bastante reducida para el extenso período comprendido entre los siglos III-V d.C., siendo dicha circunstancia especialmente llamativa en la superficie in urbe, donde por el momento tan solo conocemos una vivienda que podría englobarse en dicha categoría. Se trata de un dato llamativo si tenemos en cuenta la condición de la ciudad como caput provinciae 
bético hasta la segunda mitad del siglo IV-inicios del V (cuando tuvo lugar el desplazamiento de la capitalidad a la cercana Hispalis), por lo que dichas estructuras domésticas debieron existir. De hecho, el traslado de la capital fue coetáneo a una serie de importantes transformaciones identificadas en el extremo septentrional del espacio intramuros hispalense. En este sector ha podido documentarse la creación de, al menos, tres suntuosas domus (con unas dimensiones que oscilaban entre $500 \mathrm{y}$ $1000 \mathrm{~m}^{2}$ ) surgidas a raíz de las anexión de varias viviendas preexistentes (González 2011: 372 ss. y 403-406).

En principio, y como ya hemos señalado previamente, no podemos precisar si las clases cordobesas más acomodadas optaron por residir mayoritariamente en el área suburbana y periurbana aledaña a la ciudad, o bien, en determinadas zonas in urbe por ahora escasamente conocidas, como es el entorno inmediato a los complejos civil y episcopal, situados en el extremo meridional de la ciudad y junto al río (fig. 3).

Tales dudas son extrapolables a los últimos siglos de la Antigüedad Tardía. Si bien es cierto que los siglos VI-VII d.C. supusieron la construcción de varias estructuras in urbe vinculadas a las élites, su funcionalidad doméstica no ha podido ser totalmente confirmada. Destaca una construcción ornamentada con, al menos, un rico mosaico que se ha venido fechando en pleno siglo VI d.C., ya que en caso de tratarse de una domus (una de las dos hipótesis que barajamos) nos encontraríamos ante un inmueble bastante excepcional en la península ibérica. Tampoco podemos olvidar el hallazgo en los últimos años de varios edificios compactos cuyo uso público, semipúblico o privado no ha podido determinarse con precisión. En caso de que tuviesen un carácter residencial, se sumarían a un creciente catálogo de edificaciones que están empezando a salir a la luz tanto en el espacio intramuros, como en el suburbio, de otras ciudades hispanas.

La arquitectura doméstica vinculada a las clases más privilegiadas se alternó en el espacio con otras estructuras residenciales pertenecientes a grupos acomodados, pero con menor capacidad económica. En el estado actual de la investigación, el grueso de la información es la relativa a los siglos III-IV d.C., cuando tuvo lugar tanto la reforma puntual de determinadas $d o$ mus como la construcción de algunas viviendas; estas últimas, caracterizadas por el empleo de pavimentos musivos de carácter geométrico y por su articulación alrededor de patios mal conocidos. Destaca su instalación en determinados ejes viarios $\mathrm{y}$, sobre todo, en antiguos complejos monumentales públicos, siendo en ambos casos un fenómeno regulado en mayor o menor medida por las autoridades. Más difícil es determinar el lugar de residencia de este grupo social a partir del siglo V d.C. en adelante, cuando el registro arqueológico atestigua la aparente inutilización de gran parte de dichas construcciones.

En cuanto a las edificaciones residenciales de carácter popular, las dificultades a la hora de detectarlas en época clásica son extensibles a épocas posteriores, puesto que la documentación se limita en gran medida a algunas unidades habitacionales polifuncionales con pocas divisiones internas. A esta reducida muestra quizás habría que sumar un variado elenco de estructuras datadas hacia los siglos IV-V y VI-VII d.C. y que consisten generalmente en pavimentos o muros aislados, por lo que su funcionalidad doméstica no ha podido ser confirmada (Ruiz Bueno 2016: 303 ss. y 420 ss.). Si las datadas en la cuarta y quinta centuria presentan una distribución espacial bastante heterogénea, aquellas adscritas a la sexta y séptima centuria son especialmente abundantes en la mitad meridional de la ciudad romana, lo que podría apuntar hacia una especial concentración de la población en el entorno del centro de poder tardoantiguo. No obstante, ello no quiere decir que el resto de la superficie in urbe quedase deshabitada, ya que el registro arqueológico refleja un espacio intramuros "donde conviven y alternan sin solución de continuidad espacios ocupados, ya sean de carácter productivo, habitacional, vertederos, las nuevas construcciones sacras, y espacios vacios" (Sánchez 2011: 104). Aún más difícil es determinar el patrón de ocupación del espacio suburbano y periurbano, donde debió de vivir un indeterminado porcentaje de la población cordobesa.

\section{Agradecimientos}

La elaboración del presente artículo hubiese sido imposible sin la ayuda de un variado elenco de profesionales a quienes agradecemos sus distintas aportaciones y comentarios: al Dr. J.F. Murillo (Gerencia Municipal de Urbanismo del Ayuntamiento de Córdoba), quien nos permitió la consulta de los informes de excavación inéditos depositados en la Gerencia Municipal de Urbanismo del Ayuntamiento de Córdoba, y a los arqueó$\operatorname{logos}$ A.J. Criado, A. León, P.F. Marfil, I. Martín, A. Molina, A.J. Montejo, M. Moreno Almenara, A. Moreno Rosa, E. Ruiz Nieto, P.J Soriano, S. Vargas y J. Valderrama, por proporcionaros copia de la información solicitada sobre las intervenciones arqueológicas por ellos dirigidas. 


\section{BIBLIOGRAFÍA}

Acién, M. y Vallejo, A. (1998): "Urbanismo y estado islámico: de Corduba a Qurtuba-Madinat al-Zahra", en P. Cressier y M. García-Arenal (eds.), Genèse de la ville islamique en al-Andalus et au Maghreb occidental: 107-136. Madrid, Casa de Velázquez y Consejo Superior de Investigaciones Científicas.

Alba, M. (2004): "Arquitectura doméstica de Emerita”, en X. Dupré (ed.), Las capitales provinciales de Hispania, vol. 2. Mérida, Colonia Augusta Emerita: 67-83. Roma, L'Erma di Bretschneider.

Alba, M. (2005): "La vivienda en Emerita durante la Antigüedad Tardía: propuesta de un modelo para Hispania", en J.M a . Gurt y A.V. Ribera (coords.), VI Reunió d'Arqueologia Cristiana Hispànica: 121150. Valencia (2003), Barcelona, Institut d'Estudis Catalans.

Alba, M. (2007): "Diacronía de la vivienda señorial de Emerita (Lusitania, Hispania): Desde las domus alto imperiales y tardoantiguas a las residencias palaciales omeyas (siglos I-X)", en G.P. Brogiolo y A. Chavarría (coords.), Archaeologia e societá tra Tardo Antico e Alto Medioevo. Documenti di Archeologia 44: 163-192. Padova (2005), Mantova, Società Archeologica Padana.

Alba, M. (2011): "Los espacios domésticos en la ciudad visigoda de Emerita (ss. V-VIII)", en J.Ma Álvarez y P. Mateos (eds.), Congreso Internacional 1910-2010. El yacimiento emeritense: 521-546. Mérida (2010), Mérida, Museo Nacional de Arte Romano.

Amador de los Ríos, J. y Amador de los Ríos, R. (1879): Monumentos Latino-Bizantinos de Córdoba. Madrid, Real Academia de Bellas Artes de San Fernando.

Aparicio, L. (1995): “Dos excavaciones arqueológicas de urgencia en la calle Blanco Belmonte de Córdoba: $\mathrm{n}^{\circ} 4$ y n ${ }^{\circ}$ s. 22 y 24". Anuario Arqueológico de Andalucía 1992, vol. III: 224-234.

Aparicio, L. (1996): Informe de Intervención Arqueológica de urgencia c/Góngora $n^{\circ} 8$, Córdoba. Informe administrativo (inédito) depositado en la Delegación Provincial de Cultura de la Junta de Andalucía en Córdoba. Expediente: 3181.

Arce, J. (2010): "El complejo residencial tardorromano de Cercadilla (Corduba)", en D. Vaquerizo (ed.), Las áreas suburbanas en la ciudad histórica. Topografia, usos y función. Monografías de Arqueología Cordobesa 18: 397-411. Córdoba (2010), Córdoba, Universidad de Córdoba.
Arce, J.; Chavarría, A. y Ripoll, G. (2007): "The urban domus in late antique Hispania: examples from Emerita, Barcino and Complutum", en L. Lavan, L.Özgenel y A. Sarantis (eds.), Housing in Late Antiquity. From Palaces to Shops. Late Antique Archaeology 3.2: 305-334. Leiden-Boston, Brill.

Ayerbe, R. (2009): "Solares de "Santa Catalina" y de la calle Berzocana, 3", en R. Ayerbe, T. Barrientos y F. Palma (eds.), El foro de Augusta Emerita. Génesis y evolución de sus recintos monumentales. Anejos de Archivo Español Arqueología 53: 68-103. Mérida, Instituto de Arqueología de Mérida.

Azkarate, A. y Quirós, J.A. (2001): “Arquitectura doméstica altomedieval en la Península Ibérica. Reflexiones a partir de las excavaciones arqueológicas de la catedral de Santa María de Vitoria-Gasteiz, País Vasco". Archeologia Medievale 28: 25-60.

Baldassarri, P. (2011): “Archaeological Excavations at Palazzo Valentini. A Residential Area in the Shade of the Trajan's Forum", en M. Sahin (ed.), $11^{\text {th }}$ International Colloquium on Ancient Mosaics. Mosaics of Turkey and Parallel Developments in the Rest of the Ancient and Medieval World: Questions of Iconography, Style and Technique from the Beginnings of Mosaic until the Late Byzantine Era: 43-47. Bursa (2009), Istambul, Yayinlari.

Baldini, I. (2001): La domus tardoantica: forme e rappresentazioni dello spazio domestico nelle città del Mediterraneo. Bologna, University Press Bologna.

Baldini, I. (2005): L'architettura residenziale nelle città tardoantiche. Roma, Carocci.

Beltrán de Heredia, J. (2013): “Barcino, de colònia romana a sede regia visigoda, medina islàmica i ciutat comtal: una urbs en transformació". Quarhis 9: 16-118.

Beltrán de Heredia, J. (2014): "Edilizia residenziale tardoantica a Barcellona: il palatia di Barcino", en P. Pensabene y C. Sfameni (a cura di), La villa restaurata e i nuovi studi sull'edilizia residenziale tardoantica: 467-476. Piazza Armerina (2012), Bari, Edipuglia.

Beltrán de Heredia, J. (2015): "Novetats sobre el fórum de Barcino: la cúria i altres edificis públics". Quarhis 11: 126-146.

Bermúdez, J.M.; Ventura, A.; Marfil, P.F., y González, C. (1991): "Avance de resultados de la excavación de urgencia en calle Ambrosio de Morales 4, recayente a calleja de Munda (Córdoba)". Antiquitas 2: 50-61.

Bowes, K. (2010): Houses and Society in the Later Roman Empire. London, Duckworth. 
Brogiolo, G.P. (2011): Le origini della città medievale. PCA Studies 1. Mantova, Societá Archeologica.

Caballero, L.; Murillo, I.; Utrero, Mª.A.; Peláez, F.; Arce, F.; Monteira, I.; Moreno, F.; Martín, R.; Lucena, J.M. y Westman, A. (2007): Estudio de Arqueología de la Arquitectura del convento de Santa Clara de Córdoba. Madrid, Fundación Caja Madrid.

Cánovas, A. (2010): “La arquitectura doméstica de la zona occidental de Colonia Patricia Corduba", en D. Vaquerizo y J.F. Murillo (eds.), El anfiteatro romano de Córdoba y su entorno urbano. Análisis arqueológico (ss. I-XIII d.C.). Monografias de Arqueología Cordobesa 19, vol. II: 415-438. Córdoba (2010), Córdoba, Universidad de Córdoba.

Carrasco, I. (2001): “Intervención arqueológica de urgencia en un solar sito en calles Ángel de Saavedra, Rey Heredia y cuesta de Pero Mato (Casa Carbonell) de Córdoba". Anuario Arqueológico de Andalucía 1996, vol. III: 97-109.

Carrillo, J.R. (1999): "Evolución de la arquitectura doméstica en Colonia Patricia Corduba", en F.R. García, y F. Acosta (coords.), Córdoba en la historia: la construcción de la urbe: 37-74. Córdoba (1997), Córdoba, Ayuntamiento de Córdoba.

Castro, E. y Cánovas, A. (2009-2010): “La domus del Parque Infantil de Tráfico (Córdoba)". Anejos de Anales de Arqueología Cordobesa 2: 121-140.

Castro, E. y Carrillo, J. R. (2005): "Intervención Arqueológica de Urgencia en el patio occidental del colegio de Santa Victoria”. Anuario Arqueológico de Andalucía 2002, vol. III: 350-364.

Corrales, A. (2016): La arquitectura doméstica de Augusta Emerita. Anejos de Archivo Español de Arqueología 76. Madrid, Consejo Superior de Investigaciones Científicas.

Correia, V.H. (2010): A arquitectura Doméstica de Conimbriga e as Estructuras Económicas e Sociais da Cidade Romana, Tesis Doctoral, Universidade de Coimbra. Disponible en: https://estudogeral.sib. uc.pt/handle/10316/18134

Cortés, A. (2011): "L'arquitectura domèstica de la ciutat romana de Barcino". Quarhis 7: 16-66.

Cortés, A. (2014): “Clasificación tipológica de la arquitectura doméstica romana. Reflexiones a partir de las ciudades del NE peninsular". Pyrenae 45.2: 5963. DOI: 10.1344/Pyrenae2014.vol45num 2.3

Criado, A. J. (2010): Informe Previo. Actividad Arqueológica Preventiva, cl María Cristina $n^{o} 4$, Córdoba. Informe administrativo (inédito) depositado en la Gerencia Municipal de Urbanismo del Ayuntamiento de Córdoba. Expediente: AAPRE/52/08.

De Matteis, L.M. (2004): Mosaici di Cos. Dagli scavi delle missioni italiane e tedesche (1900-1945). Atene, Scuola Archeologica Italiana di Atene.

Diarte, P. (2012): La configuración urbana de la Hispania tardoantigua. Transformaciones y pervivencias de los espacios públicos romanos (s. III-VI d.C.). Bar International Series 2429. Oxford, Archaeopress.

Dunbabin, K. (1999): Mosaics of the Greek and Roman world. Cambridge, Cambridge University.

Ellis, S. (1998): "Power-broking and the reuse of public buildings in Late Antiquity", en N. Cambi y E. Marin (eds.), Acta XIII Congressus internationalis archaeologiae christianae: 233-239. Split-Poreč (1994), Città del Vaticano, Pontificio Istituto di Archeologia Cristiana.

Ellis, S. (2006): "Middle class houses in Late Antiquity", en W. Bowden, A. Gutteridge y C. Machado (eds.), Social and Political Life in Late Antiquity. Late Antique Archaeology, vol. 3.1: 413-437. Leiden-Boston, Brill.

Feijoo, S. (2000): “Intervención arqueológica en la zanja para canalización de aguas de la c/ Nerja. Unas termas de época visigoda extramuros de la ciudad". Memoria 4: Excavaciones arqueológicas en Mérida: 333-357.

Fernández, P.A. (2003): La casa romana. Madrid, Akal.

Fernández, P.A. (2011): "La casa romana: las formas arquitectónicas y los modos de vida", en $\mathrm{M}^{\mathrm{a}}$.D. Baena, C. Márquez y D. Vaquerizo (eds.), Córdoba, reflejo de Roma. Catálogo de la exposición: 236-239. Córdoba (2011), Córdoba, Ayuntamiento de Córdoba, Consejería de Cultura de la Junta de Andalucía, Fundación Provincial de Artes Plásticas Rafael Botí, Fundación Viana y Universidad de Córdoba.

Fuertes, M'. C. e Hidalgo, R. (2010): "La transformación del paisaje del área noroccidental cordobesa y del palacio imperial de Maximiano tras la caída de la Tetrarquía”, en A. García, R. Izquierdo, C. Olmo y D. Peris (eds.), Espacios urbanos en el occidente mediterráneo (s. VI-VIII): 165-172. Toledo (2009), Toletvm visigodo.

García-Dils, S. (2015): Colonia Augusta Firma Astigi. La evolución urbana de Écija desde la Protohistoria hasta la Antigüedad Tardía. Serie Historia y Geografia 308. Sevilla, Universidad de Sevilla.

García Merino, C. (2007): "Crecimiento urbano, abastecimiento de agua y territorio en Uxama Argaela", 
en M. Navarro y J.J. Palao (coords.), Villes et territoires dans le bassin du Duoro á l'époque romaine: 203-238. Bordeaux (2004), Bordeaux, Ausonius.

García Vargas, E. (2012): "La Sevilla tardoantigua diez años después (2000-2010)", en J. Beltrán y O. Rodríguez (eds.), Hispaniae urbes: Investigaciones arqueológicas en ciudades históricas: 881-925. Sevilla, Universidad de Sevilla.

García Vera, J. (2003): Informe-Memoria de resultados. Intervención Arqueológica de Urgencia en el solar situado en la calle Cardenal González $n^{\circ} 2$ y 4 de la ciudad de Córdoba. Informe administrativo (inédito) depositado en la Gerencia Municipal de Urbanismo del Ayuntamiento de Córdoba. Expediente: $863 / 1 / 03$.

González, D. (2011): Forma Urbis Hispalensis. El urbanismo de la ciudad romana de Hispalis a través de los testimonios arqueológicos. Sevilla, Universidad de Sevilla y Fundación Focus-Abengoa.

Gutiérrez, S. (2012): “Gramática de la casa. Perspectivas de análisis arqueológico de los espacios domésticos medievales en la península Ibérica (siglos VIIXIII)". Arqueología de la Arquitectura 9: 139-164. DOI: 10.3989 /arqarqt.2012.11602

Hidalgo, R. (1993): "Nuevos datos sobre el urbanismo de Colonia Patricia Corduba: excavación arqueológica en la calle Ramírez de las Casas-Deza, 13”. Anales de Arqueología Cordobesa 4: 91-134.

Hidalgo, R. (2014): “Aspetti dell' interpretazione del complesso palatino di Cercadilla a Cordova", en P. Pensabene y C. Sfameni (coords.), La villa restaurata e i nuovi studi sull'edilizia residenziale tardoantica: 533-542. Piazza Armerina (2012), Bari, Edipuglia.

Jiménez, J. L.; Ruiz, Ma. D. y Moreno, M. (1996): "Nuevos avances en el conocimiento sobre el urbanismo de Colonia Patricia Corduba en el sector ocupado por el templo romano". Anales de Arqueología Cordobesa 7: 115-139.

León, A.; Murillo, J.F. y Vargas, S. (2014): "Patrones de continuidad en la ocupación periurbana de Córdoba entre la Antigüedad y la Edad Media: 1. Los sistemas hidráulicos", en D. Vaquerizo, J.A. Garriguet y A. León (eds.), Ciudad y territorio: transformaciones materiales e ideológicas entre la época clásica y el Altomedievo. Monografías de Arqueología Cordobesa 20: 137-184. Córdoba, Universidad de Córdoba.

López Cuevas, F. (2013): "La almunia cordobesa, entre las fuentes historiográficas y arqueológicas". Onoba 1: 243-260.
López López, I. Ma (1998): Aproximación al conocimiento de la Córdoba romana: el ejemplo de la Casa Carbonell. Publicación en microficha número 163, Córdoba, Universidad de Córdoba.

López López, I. Ma. y Morena, J. A. (1996): "Resultados de la Intervención Arqueológica de Urgencia realizada en el solar $n^{\circ} 3$ de la calle Saravia (Córdoba)". Antiquitas 7: 93-114.

López Monteagudo, G. (2010): "Los mosaicos romanos de la Colonia Augusta Firma Astigi. Un nuevo volumen del corpus de mosaicos romanos de España". Boletín de la Real Academia de Ciencias, Bellas Artes y Buenas Letras "Luis Vélez de Guevara" 6: 367-388.

López Rey, N. (1995): "Informe de la I.A.U. realizada en el solar $\mathrm{n}^{\circ}$ 14-16 de la calle Alfonso XIII de Córdoba". Anuario Arqueológico de Andalucía 1992, vol. III: 200-210.

Macias, J.M. (2013): “La medievalización de la ciudad romana”, en J.M. Macias y A. Muñoz (eds.), Tarraco christiana civitas. Documenta 24: 123-148. Tarragona, Institut Català d'Arqueologia Clàssica.

Magalhães, F. (2010): Arquitectura doméstica em Bracara Augusta. Tesis Doctoral, Universidade do Minho. Disponible en: http://repositorium.sdum. uminho.pt/handle/1822/13619

Mañas, I. (2009): "Pavimentos decorativos de Itálica. Una fuente para el estudio del desarrollo urbano de la ampliación adrianea". Romula 8: 179-198.

Mar, R. y Guidi, J. (2010): "Formación y usos del espacio urbano tardoantiguo en Tarraco", en A. García, R. Izquierdo, C. Olmo y D. Peris (eds.), Espacios urbanos en el occidente mediterráneo (s. VI-VIII): 173-182. Toledo, Toletvm visigodo.

Mar, R. y Perich, A. (2014) "Casa y ciudad en la Hispania tardoantigua. La evolución de los modelos tipológicos", en P. Pensabene y C. Sfameni (coords.), La villa restaurata e $i$ nuovi studi sull'edilizia residenziale tardoantica: 441-452. Piazza Armerina (2012), Bari, Edipuglia.

Marfil, P. F. (1996a): Informe y memoria cientifica de la I.A.U. Iglesia del convento de Santa Clara, c/ Rey Heredia, Córdoba. Informe administrativo (inédito) depositado en la Delegación Provincial de Cultura de la Junta de Andalucía en Córdoba. Expediente: 1370 .

Marfil, P. F. (1996b): "La iglesia paleocristiana de Santa Catalina en el Convento de Santa Clara, (Córdoba)". Caetaria 1: 33-45.

Marfil, P. F. (1996c): "El templo paleocristiano descubierto en la antigua iglesia del convento de Santa 
Clara, de Córdoba". Boletín de la Real Academia de Córdoba 67: 197-210.

Marín, P. (2011): “Una aproximación a la musivaria tardoantigua en Iliberis. Los mosaicos de la villa de los Vergeles (Granada)". Arqueología y Territorio 8: 173-186.

Marot, T. (2000-2001): "La península ibérica en los siglos V-VI: consideraciones sobre provisión, circulación y usos monetarios". Pyrenae 31-32: 133-160.

Martín, I. (2012): Actividad Arqueológica Preventiva en la plaza Ramón y Cajal $n^{\circ} 2$ de Córdoba. Informe y Memoria. Informe administrativo (inédito) depositado en la Gerencia Municipal de Urbanismo del Ayuntamiento de Córdoba. Expediente: P543/2007.

Melchor, E. (1994): El mecenazgo cívico en la Bética: la contribución de los evergetas al desarrollo de la vida municipal. Córdoba, Instituto de Historia de Andalucía y Servicio de Publicaciones de la Universidad de Córdoba.

Melchor, E. (2009): "Las élites municipales hispanorromanas a fines de la República y en el Alto Imperio: ideología y conductas socio-políticas", en J. Andreu, J. Cabrero e I. Rodà (eds.), Hispania: las provincias hispanas en el mundo romano. Documenta 11: 391-410. Tarragona, Institut Català d'Arqueologia Clàssica.

Melchor, E. (2016): “François Jacques tenía razón: sobre el no declinar de las élites locales y de la vida municipal durante el siglo II y el primer tercio del siglo III d.C.", en J. Andreu (ed.), Oppida Labentia. Transformaciones, cambios y alteración en las ciudades hispanas entre el siglo II y la tardoantigüedad: 443-487. Uncastillo, Fundación Uncastillo.

Molina, A. (2002): Informe-Memoria de la Intervención Arqueológica de Urgencia realizada en la calle Valladares, $n^{\circ}$ 6, Córdoba. Informe administrativo (inédito) depositado en la Gerencia Municipal de Urbanismo del Ayuntamiento de Córdoba. Expediente: 523/1/03.

Molina, A. y Sánchez, I. Ma . (2002-2003): “Una aportación a las necrópolis tardorromanas de Corduba: el sector funerario de la calle Lucano $\mathrm{n}^{\mathrm{0}} 7$ y 9 de Córdoba". Anales de Arqueología Cordobesa 1314: 355-389.

Montejo, A. J. (1998): Informe Sucinto de los resultados obtenidos durante la Intervención Arqueológica de Urgencia en Magistral González Francés $n^{\circ}$ 23. Córdoba. Informe administrativo (inédito) depositado en la Delegación Provincial de Cultura de la Junta de Andalucía en Córdoba. Expediente: 1562 .
Montejo, A. J. (2006): Informe sucinto de los resultados obtenidos durante la Actividad Arqueológica Preventiva en la calle Lindo $n^{\circ} 4$ (Córdoba). Informe administrativo (inédito) depositado en la Gerencia Municipal de Urbanismo del Ayuntamiento de Córdoba. Expediente: AAPRE/119/05.

Monterroso, A. J. (2002): "El edificio como cantera: historia de un saqueo", en A. Ventura, C. Márquez, A. Monterroso y M.A. Carmona (eds.), El teatro romano de Córdoba. Catálogo de la exposición: 147160. Córdoba, Universidad de Córdoba.

Monterroso, A. J y Cepillo, J. J. (2002): “La ocupación medieval", en A. Ventura, C. Márquez, A. Monterroso y M.A. Carmona (eds.), El teatro romano de Córdoba. Catálogo de la exposición: 161-172. Córdoba, Universidad de Córdoba.

Moreno Almenara, M. (2018, e.p.): “Actividad Arqueológica Puntual realizada en apoyo a la puesta en valor de la domus de la llamada Casa Castejón (antiguo Palacio del Bailío) de Córdoba”. Anuario Arqueológico de Andalucía 2011.

Moreno Almenara, M. y González, M.L. (2001): “Intervención Arqueológica de Urgencia en la plaza de Maimónides, esquina c/ Cardenal Salazar de Córdoba". Anuario Arqueológico de Andalucía 1997, vol. III: 163-171.

Moreno González, M. F. (1996): Aproximación al estudio de la decoración musivaria en Colonia Patricia Corduba, Publicación en microficha número 134, Córdoba, Universidad de Córdoba.

Moreno González, M. F. (1997): “Nuevas aportaciones al estudio del mosaico romano en Corduba Colonia Patricia". Archivo Español de Arqueología 70: 101-124.

Morín, J.; Silva, P.G.; Rodríguez, M.A. y Sánchez, I.M ${ }^{\mathrm{a}}$ (2014): "Evidencias arqueosismológicas en la Colonia Patricia romana de Córdoba (Valle del Guadalquivir, España)", en J.A. Alvárez y F. Martín (eds.), Una aproximación multidisciplinar al estudio de las fallas activas, los terremotos y el riesgo sísmico. Segunda reunión Ibérica sobre fallas activas y paleosismología: 159-162. Madrid, Instituto Geológico y Minero de España.

Murillo, J.F.; Carrillo, J.R.; Moreno, M.; Ruiz, D., y Vargas, S. (2002): "Los monumentos funerarios de Puerta Gallegos. Colonia Patricia Corduba", en D. Vaquerizo (coord.), Espacios y usos funerarios en el Occidente Romano, vol. II: 247-274. Córdoba (2001), Córdoba, Universidad de Córdoba.

Murillo, J.F.; Moreno, M.; Penco, F. y Martín, I. (2009): "Intervención Arqueológica de Urgencia en apoyo a 
la puesta en valor del templo romano de Córdoba". Anuario Arqueológico de Andalucía 2004, vol. I: 690-706.

Murillo, J.F.; León, A.; Castro, E.; Casal, Mª.T.; Ortiz, R. y González, A.J. (2010): "La transición de la $c i$ vitas clásica cristianizada a la madina islámica a través de las transformaciones operadas en las áreas suburbiales", en D. Vaquerizo y J.F. Murillo (eds.), El anfiteatro romano de Córdoba y su entorno urbano. Análisis arqueológico (ss. I-XIII d.C.). Monografias de Arqueología Cordobesa 19, vol. II: 503547. Córdoba, Universidad de Córdoba.

Nicolini, M. N. (1983): “À propos de la mosaïque des saisons de Cordoue: iconographie et chronologie". Mélanges de la Casa de Velázquez 19: 79-87.

Nolla, J.M. y Palahí, L. (2010): “Girona. L’arqueologia; eina per a la restitució urbanística. Del forum a la catedral", en AA.VV., Arqueología, patrimonio y desarrollo urbano: problemática y soluciones: actas del seminario de Girona, 3 de julio de 2009: 7-29. Girona (2009), Girona, Universitat de Girona.

Ortalli, J. (2003): "L'insediamento residenziale urbano nella Cispadana”, en J. Ortalli y M. Heinzelmann (coords.), Abitare in città. La Cisalpina tra imperio e medioevo. Palilia 12: 95-119. Roma (1999), Wiesbaden, Reichert.

Ortiz, L. (2011): "Una villa romana en Ronda de Marrubial. Del s. I al IV d.C.". Romula 10: 253-276.

Penco, F. (2000): "Un pavimento musivo de influencia bizantina en el antiguo convento de Santa Clara de Córdoba", en J.M ${ }^{a}$. Gurt y N. Tena (eds.), $V R e$ unió d'Arqueologia Cristiana Hispànica: $245-$ 261. Cartagena (1998), Barcelona, Institut Català d'Arqueologia Clàssica.

Penco, F. (2002): “Apuntes sobre un excepcional mosaico de influencia bizantina en el antiguo convento de Santa Clara de Córdoba". Meridies 5-6: 7-28.

Penco, R. (2005): "La villa romana de Santa Rosa. Resultados preliminares de una I.A.U. llevada a cabo en la parcela adyacente a las calles Algarrobo 4,6,8,10 y Cronista Rey Díaz, 3 de Córdoba". Anales de Arqueología Cordobesa 16: 11-34.

Pérez Martínez, M. (2012): Tarraco en la Antigüedad Tardia. Cristianización y organización eclesiástica (Siglos III a VIII). Tarragona, Arola Editors.

Pérez Navarro, C. (2003): "Evolución de una domus desde el siglo I a.C. al s. V d.C. (I.A.U. y Seguimiento Arqueológico en Pl. Pineda, 2)". Arte, Arqueología e Historia 10: 62-70.

Perich, A. (2014a): Arquitectura residencial urbana d'època tardoantiga a Hispania (segles
IV-VIII d.C). Tesis doctoral, Universitat Rovira $\mathrm{i}$ Virgili. Disponible en: https://www.tesisenred.net/ handle/10803/293906

Perich, A. (2014b): "Las transformaciones urbanas en Tarraco. El ámbito doméstico a finales del altoimperio", en S.F. Ramallo y A. Quevo (eds.), Las ciudades de la Tarraconense oriental entre los s. II-IV d.C. Evolución urbanística y contextos materiales: 119-147. Murcia, Universidad de Murcia.

Ramallo, S.F. (2000): “Arquitectura doméstica en ámbitos urbanos entre los siglos V y VIII”, en L. Caballero y P. Mateos (coords.), Visigodos y Omeyas. Un debate entre la Antigüedad Tardía y la Alta Edad Media. Anejos de Archivo Español de Arqueología 23: 367-384. Madrid, Consejo Superior de Investigaciones Científicas.

Rascón, S. y Sánchez, A.L. (2015): “Complutum: modelo urbanístico para una ciudad romana privilegiada en los siglos III-V”, en L. Brassous y A. Quevedo (eds.), Urbanisme civique en temps de crise. Les espaces publics d'Hispanie et de l'Occident romain entre les II et IV ${ }^{e}$ s. Collection de la Casa de Velázquez 149: 199-220. Madrid, Casa de Velázquez.

Ribera, A.V y Jiménez, J.L. (2012): “Valentia, ciudad romana: Su evidencia arqueológica”, en J. Beltrán y O. Rodríguez (eds.), Hispaniae urbes: Investigaciones arqueológicas en ciudades históricas: 77-120. Sevilla, Universidad de Sevilla.

Ribera, A.V. y Rosselló, M. (2009): "Valentia en el siglo VII, de Suinthila a Teodomiro", en L. Caballero, P. Mateos y Ma. A. Utrero (eds.), El siglo VII frente al siglo VII. Arquitectura. Anejos de Archivo Español de Arqueología 51: 185-203. Madrid, Consejo Superior de Investigaciones Científicas.

Rodríguez, A.; García, J.Mª ; Rodríguez, J. y Pérez, Mª . J. (2013-2014): "La villa romana de los Mondragones (Granada). Un nuevo yacimiento arqueológico en el entorno de Iliberis". Romula 12-13: 475-501.

Rojas, J.M. y Gómez, A.J. (2009): “Intervención arqueológica en la Vega Baja de Toledo. Características del centro político y religioso del reino visigodo", en L. Caballero, P. Mateos y Ma . A. Utrero (eds.), El siglo VII frente al siglo VII. Arquitectura. Anejos de Archivo Español de Arqueología 51: 4589. Madrid, Consejo Superior de Investigaciones Científicas.

Román Punzón, J. (2005): “Algunas consideraciones acerca de Eliberri en época tardoantigua". Anales de Arqueología Cordobesa 16: 161-180.

Román Rodríguez, J. (2010): “Transformaciones postadrianeas del ámbito doméstico en la Nova Urbs de 
Itálica. Una aproximación a partir de la Terra Sigillata Africana". Romula 9: 289-314.

Romero, D. (2016): La ciudad hispanorromana en el s. II d.C. Consolidación y transformación de un modelo urbano. Tesis Doctoral, Universidad de Córdoba. Disponible en: https://helvia.uco.es/ handle/10396/14222

Ruiz Bueno, M.D. (2014): "El entorno del decumanus maximus de Colonia Patricia Corduba: ¿evidencias de una remodelación urbanística hacia época severiana?", en D. Vaquerizo, J.A. Garriguet y A. León (eds.), Ciudad y territorio: transformaciones materiales e ideológicas entre la época clásica y el Altomedievo. Monografías de Arqueología Cordobesa 20: 41-54. Córdoba, Universidad de Córdoba.

Ruiz Bueno, M.D. (2014-2015): "El kardo maximus de Córdoba en la Antigüedad Tardía". Anales de Arqueología Cordobesa 25-26: 83-114.

Ruiz Bueno, M.D. (2016): Topografía, imagen y evolución urbanística de la Córdoba clásica a la tardoantigua (ss. II-VII d.C.). Tesis Doctoral, Universidad de Córdoba. Disponible en: https://helvia.uco. es/handle/10396/14142?show=full

Ruiz Bueno, M.D. (2017): “Actividad sísmica en el mediodía ibérico durante el siglo III d.C. La incidencia arqueológica en Corduba (Córdoba)". Pyrenae 48.2: 29-51. DOI: 10.1344/Pyrenae2017.vol48num 2.2

Ruiz Bueno, M.D. y González Gutiérrez, C. (2017): "De "iglesia" tardoantigua a mezquita califal. Revisión arqueológica de las estructuras conservadas en calle Rey Heredia 20 (Córdoba)", Munibe 68: 251272. DOI: $10.21630 /$ maa.2017.68.13

Ruiz Nieto, E. (1994): Informe. Intervención Arqueológica de Urgencia en Plaza de la Compañía, 1 y 2 (Córdoba). Informe administrativo (inédito) depositado en la Delegación Provincial de Cultura de la Junta de Andalucía en Córdoba. Expediente: 3051.

Ruiz Nieto, E. (1999): "Intervención Arqueológica de Urgencia en el solar sito en la c/ Duque de Fernán Núñez, 11-13 (Córdoba)". Anuario Arqueológico de Andalucía 1995, vol. III: 125-130.

Ruiz Nieto, E. (2002): “Intervención Arqueológica de Urgencia en c/ San Pablo, 17 (Córdoba)". Anuario Arqueológico de Andalucía 1999, vol. III: 157-163.

Ruiz Nieto, E. (2003): Informe de la Intervención Arqueológica de Urgencia en la c/ Duque de Hornachuelos, 8, (Córdoba). Informe administrativo (inédito) depositado en la Gerencia Municipal de Urbanismo del Ayuntamiento de Córdoba. Expediente: 4403/1/03.
Ruiz Osuna, A.B. y Ruiz Bueno, M.D. (2018): "Novedades de musivaria cordobesa: puesta al día de su estudio y su uso como recurso patrimonial", en J.M ${ }^{\mathrm{a}}$. Álvarez y M $\mathrm{M}^{\mathrm{a}}$.L. Neira (coord.), Estudios sobre mosaicos romanos. Dimas Fernández-Galiano. In Memoriam: 329-372, Madrid, Esfera de los Libros.

Sáez, P.; Ordóñez, S. y García-Dils, S. (2005): "El urbanismo de la Colonia Augusta Firma Astigi: Nuevas perspectivas". Mainake 27: 89-112.

Salinas, J.M". (2005): "El sector septentrional de la villa romana de Santa Rosa". Anales de Arqueología Cordobesa 16: 35-54.

Saliou, C. (2005): "Identité culturelle et paysage urbain: remarques sur les processus de transformation des rues à portiques dans 1'Antiquité Tardive". Syria 82: 207-224.

Sánchez, I. Ma (2006): “La cristianización de la topografía funeraria en las provincias occidental del Imperio: exemplum cordubense". Tesis Doctoral, Universidad de Córdoba. Disponible en: https://helvia. uco.es/xmlui/handle/10396/3657?show=full

Sánchez, I.M" . (2011): "La desfiguración de la ciudad clásica. Los nuevos espacios urbanos de Corduba en la Antigüedad Tardía”, en $\mathrm{M}^{\mathrm{a}}$.D. Baena, C. Márquez y D. Vaquerizo (eds.), Córdoba, reflejo de Roma. Catálogo de la exposición: 100-107. Córdoba (2011), Córdoba, Ayuntamiento de Córdoba, Consejería de Cultura de la Junta de Andalucía, Fundación Provincial de Artes Plásticas Rafael Botí, Fundación Viana y Universidad de Córdoba.

Santangeli, R. (2011): Edilizia residenziale in Italia nell' altomedioevo. Roma, Carocci.

Saradi, H. (1998): "Privatisation and subdivision of urban properties in the early Byzantine centuries: social and cultural implications". Bulletin of the American Society of Papyrologists 35: 17-43.

Secilla, R. y Márquez, C. (1991): "Una casa romana en el S.E. de Colonia Patricia Corduba: un ejemplo a seguir", en AA.VV, La casa urbana hispanorromana: ponencias y comunicaciones: 337-342. Zaragoza (1988), Zaragoza, Institución Fernando el Católico.

Soriano, P. J. (2003): “Intervención arqueológica de urgencia en el antiguo convento del Corpus Christi (futura Fundación Gala) de Córdoba". Anuario Arqueológico de Andalucía 2000, vol. III: 447-455.

Utrero, M' ${ }^{\mathrm{a}}$. A. (2009): "Las iglesias cruciformes del siglo VII en la Península Ibérica. Novedades y problemas cronológicos y morfológicos de un tipo arquitectónico", en L. Caballero, P. Mateos y Ma . A. Utrero (eds.), El siglo VII frente al siglo VII. Arquitectura. Anejos de Archivo Español de Arqueología 
51: 133-154. Madrid, Consejo Superior de Investigaciones Científicas.

Valderrama, J. (2007): Informe técnico preliminar de resultados de Actividad Arqueológica Preventiva en la calle Olmillo $n^{\circ} 2$ de Córdoba. Informe administrativo (inédito) depositado en la Gerencia Municipal de Urbanismo del Ayuntamiento de Córdoba. Expediente: AAPRE/90/96.

Vaquerizo, D. (2004): “Arquitectura doméstica y funeraria”, en X. Dupré (ed.), Las capitales provinciales de Hispania, vol. I. Córdoba, Colonia Patricia Corduba: 81-94. Roma, L'Erma di Bretschneider.

Vaquerizo, D. (2014): “Ciudad y territorio en el Valle Medio del Betis: apuntes al hilo de una realidad dual, pero esquiva", en D. Vaquerizo, J.A. Garriguet y A. León (eds.), Ciudad y territorio: transformaciones materiales e ideológicas entre la época clásica y el Altomedievo. Monografías de Arqueología Cordobesa 20: 11-40. Córdoba, Universidad de Córdoba.

Vaquerizo, D. y Murillo, J. F. (2010): “Ciudad y suburbia en Corduba. Una visión diacrónica (siglos II a.C.-VII d.C.)", en D. Vaquerizo (ed.), Las áreas suburbanas en la ciudad histórica. Topografia, usos y función. Monografias de Arqueología Cordobesa 18: 455-522. Córdoba (2010), Córdoba, Universidad de Córdoba.

Vargas, S. (2010): "El vicus del suburbium occidental de Colonia Patricia visto a través de sus conjuntos cerámicos", en D. Vaquerizo y J.F. Murillo (eds.), El anfiteatro romano de Córdoba y su entorno urbano. Análisis arqueológico (ss. I-XIII d.C.).
Monografias de Arqueología Cordobesa 19, vol. II: 450-466. Córdoba, Universidad de Córdoba.

Ventura, A. (1991): "Resultados del Seguimiento Arqueológico en el solar de c/ Ángel de Saavedra $\mathrm{n}^{\mathrm{o}}$ 10, Córdoba". Anales de Arqueología Cordobesa 2: 253-290.

Ventura, A. (1996): El abastecimiento de agua a la Córdoba romana II. Acueductos, ciclo de distribución y urbanismo. Córdoba, Universidad de Córdoba.

Ventura, A. (1998). Informe de la Intervención Arqueológica de Urgencia en el solar destinado a ampliación de la Excma. Diputación Provincial de Córdoba. Informe administrativo (inédito) depositado en la Delegación Provincial de Cultura de la Junta de Andalucía en Córdoba. Expediente: 1341/1.

Ventura, A. y Carmona, S. (1992): "Resultados sucintos de la excavación arqueológica de urgencia en los solares de la calle Blanco Belmonte 4-6 y Ricardo de Montis 1-8, Córdoba. El trazado del cardo máximo de la Colonia Patricia Corduba". Anales de Arqueología Cordobesa 3: 199-241.

Ventura, A. y Pizarro, G. (2010): "El Aqua Augusta (acueducto de Valdepuentes) y el abastecimiento de agua a Colonia Patricia Corduba: investigaciones recientes (2000-2010)", en AA.VV, Las técnicas y las construcciones en la ingeniería romana. V congreso de las obras públicas romanas: 177-203. Madrid, Fundación de la Ingeniería Técnica de Obras.

Vizcaíno, J. (2009): La presencia bizantina en Hispania (siglos VI-VII). La documentación arqueológica. Antigüedad y Cristianismo 24. Murcia, Universidad de Murcia. 